\title{
Bond Characterization of Chromium-Fischer Carbene Complexes: A Combined Study of Experiment and Theory
}

\author{
Chih-Chieh Wang, Yu Wang,* Hui-Jean Liu, Kuan-Jiuh Lin, Liang-Kuei Chou, and \\ Kin-Shing Chan
}

Department of Chemistry, National Taiwan University, Taipei, Taiwan, ROC

Received: June 5, 1997; In Final Form: September 3, $1997^{\circledR}$

\begin{abstract}
Four pentacarbonyl chromium-carbene complexes, $(\mathrm{CO})_{5} \mathrm{CrC}\left(\mathrm{XR}^{\prime}\right) \mathrm{R}$, have been studied via $\mathrm{X}$-ray diffraction and molecular orbital calculations. One of the carbene complexes $\left(\mathrm{XR}^{\prime}=\mathrm{OCH}_{3}, \mathrm{R}=-(\mathrm{C} \equiv \mathrm{CPh})\right.$ ) has been investigated extensively at $110 \mathrm{~K}$ by $\mathrm{X}$-ray diffraction using Mo K $\alpha$ radiation. The electron density distribution of this compound as well as the asphericity in electron density around the $\mathrm{Cr}$ atom is clearly demonstrated by deformation density and the Laplacian of electron density. The comparison between experiment and theory is made in terms of deformation density, topological properties, and d orbital populations of Cr. Further chemical bond characterization is based on quantum mechanical molecular orbital calculation and properties associated with bond critical points. The $\pi$ bond character of a metal carbene can be best represented by a $\mathrm{Cr}-\mathrm{C}-\mathrm{X}$ three-centered four-electron bond with the $\pi$ electron density mainly located at either the $\mathrm{d}_{y z}$ orbital of $\mathrm{Cr}$ or the $\mathrm{p}_{z}$ orbital of $\mathrm{X}$ in the carbene ligand. This makes the carbene carbon an electrophilic site in the $\mathrm{p}_{\pi}$ direction. The resemblances and differences between amino- $(X=N)$ and alkoxy $-(X=O)$ carbene complexes are of special interest. Because the energy of $\pi^{*} \mathrm{C}-\mathrm{N}$ orbital is fairly close to that of the $\pi^{*} \mathrm{C} \equiv \mathrm{O}$ (carbonyl on $\mathrm{Cr}$ ), the $\pi$ bond character is delocalized toward the $\mathrm{M}-\mathrm{C}_{\text {carbonyl }}$ at the trans position i.e., $\mathrm{O}=\mathrm{C}=\mathrm{M}-$ $\mathrm{C}=\mathrm{N}$ in the amino carbene case; this is in accord with the shortening of bond lengths of the trans $\mathrm{M}-\mathrm{C}_{\text {carbonyl }}$ for many amino-carbene complexes. The $\pi$ bond-delocalization is also illustrated by the Fermi hole distribution. The bond dissociation energies of these carbene complexes are calculated at the CASSCF level and with the density functional method (DFT). The relative orbital energies are also compared with photoelectron spectroscopy (PES) data. The values based on DFT using the transition-state approximation give the best agreement with the experimental results.
\end{abstract}

\section{Introduction}

Transition metal carbene complexes have been extensively studied primarily due to their importance in catalysis and their use in organic synthesis ${ }^{1-4}$. Generally, metal carbene complexes are typically divided into two types: the Fischer ${ }^{3}$ and the Schrock ${ }^{4}$-type complexes. The Fischer carbene complex is electrophilic at the carbene carbon, and the Schrock type complex is nucleophilic at the carbene carbon. It is well-known that the metal ion is normally in its low oxidation state in Fischer-type carbene complexes, and such a carbene is often stabilized by a heteroatom $\mathrm{X}$, where $\mathrm{X}=\mathrm{N}, \mathrm{O}$, and $\mathrm{S}$. On the contrary, the metal ion is often in its high oxidation state in Schrock-type carbenes. For Fischer-type carbenes, the nature of the metal-carbene bond and of the $\mathrm{C}-\mathrm{X}$ bond in the carbene fragment of the ligand, $\mathrm{C}\left(\mathrm{XR}^{\prime}\right) \mathrm{R}$, are of special interest. Because of the lone-pair electrons at the heteroatom $\mathrm{X}$, the possible $\pi$ bond delocalization between $\mathrm{M}-\mathrm{C}_{\text {carbene }}$ and $\mathrm{X}-\mathrm{C}_{\text {car- }}$ bene could be formulated as a hybrid of resonance structures shown in $\mathbf{a}-\mathbf{c}$.

* To whom all correspondence should be addressed.

†Present address: Department of Chemistry, Chinese University of Hong Kong, Shatin, NT, Hong Kong.

${ }^{\otimes}$ Abstract published in Advance ACS Abstracts, November 1, 1997.

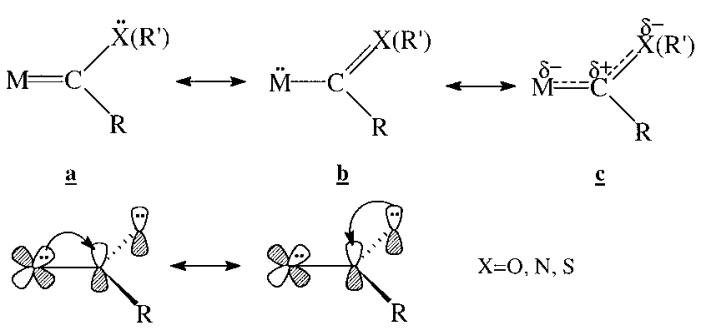

$\underline{\mathbf{a}}$ : carbene form $\quad \underline{\mathbf{b}}$ : acyl form

Earlier empirical MO calculations were reported ${ }^{5}$ on several pentacarbonyl chromium - carbene complexes $(\mathrm{CO})_{5} \mathrm{Cr}=\mathrm{CXR}^{\prime} \mathrm{R}$ $\left(\mathrm{XR}^{\prime}=\mathrm{OMe}, \mathrm{NH}_{2}, \mathrm{NMe}_{2}\right.$, and $\left.\mathrm{SMe}\right)$ in comparison with the photoelectron spectroscopy (PES) studies. ${ }^{5}$ These studies ${ }^{5}$ indicated that amino-carbenes are poorer $\pi$ acceptors than alkoxy- or alkyl-thio carbenes, and all these carbene ligands are poorer $\pi$ acceptors than carbonyl ligands. However, the same study gave a different view on the generally accepted idea of the carbene carbon being an electron deficient center. The first nonempirical calculation on a model transition metal carbene complex was introduced by Schaefer and co-workers; ${ }^{6}$ the system chosen was $(\mathrm{CO})_{3} \mathrm{NiCH}_{2}$. The result indicated that the barrier on the rotation about the $\mathrm{Ni}-\mathrm{C}_{\text {methylene }}$ axis is very small. Nakatsuji and co-workers ${ }^{7}$ later did ab initio calculations 
TABLE 1: Crystal Data for Compounds 1, 2, 3, and 4

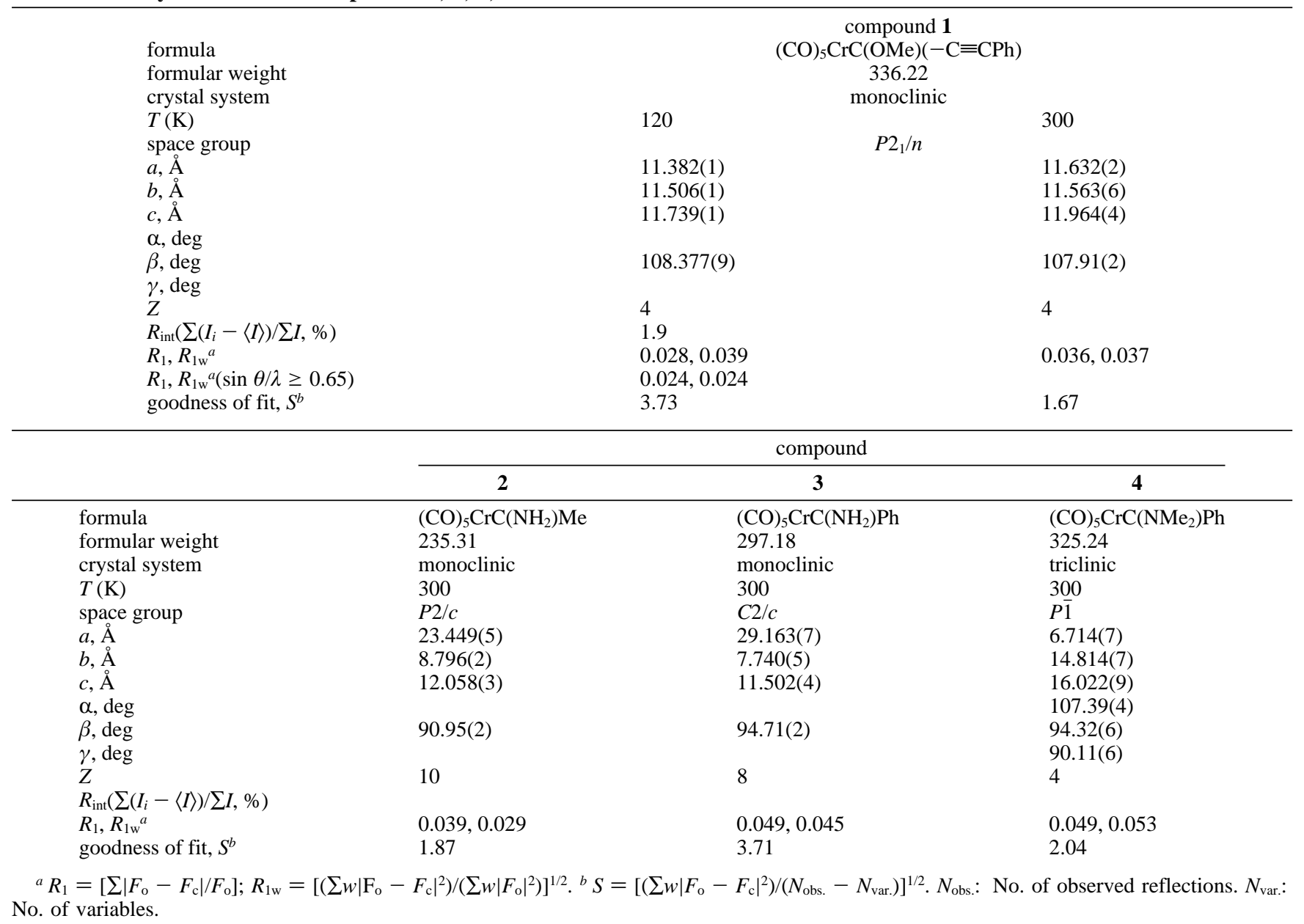

at the HFSCF level on two Fischer-type carbenes: $(\mathrm{CO})_{5} \mathrm{Cr}=\mathrm{CH}-$ $(\mathrm{OH})$ and $(\mathrm{CO})_{4} \mathrm{Fe}=\mathrm{CH}(\mathrm{OH})$. The bond energies of $\mathrm{M}-\mathrm{C}_{\text {carbene }}$ were calculated to be 44.4 and $36.8 \mathrm{kcal} / \mathrm{mol}$ for $\mathrm{Cr}$ and $\mathrm{Fe}$ respectively. The rotational barrier around the $\mathrm{M}-\mathrm{C}_{\text {carbene }}$ bond was calculated again to be very small. The electrophilic reactivity of the carbene carbon is interpreted not by the chargecontrolled but by the orbital-controlled mechanism ${ }^{7}$. Other MO calculations using extended Hückel ${ }^{8,9}$, Fenske-Hall, ${ }^{10-13}$ and HFSCF $^{14-18}$ all gave similar conclusions about the geometry and the bond description on the metal carbene bond. The first post-HF calculation on such a metal carbene system was reported by Taylor and Hall, ${ }^{19}$ where a limited CI expansion (12 configurations) was performed on a Fischer-type $(\mathrm{CO})_{5^{-}}$ $\mathrm{Mo}=\mathrm{CH}(\mathrm{OH})$ and a Schrock-type $\mathrm{CpCl}_{2} \mathrm{Nb}=\mathrm{CH}_{2}$ metal carbene. The results indicated that the former (Fischer-type) $\mathrm{M}-\mathrm{C}$ bond is bound datively between two singlet fragments (depicted as d), whereas the latter (Schrock-type) is bound covalently between two triplet fragments (depicted as e).
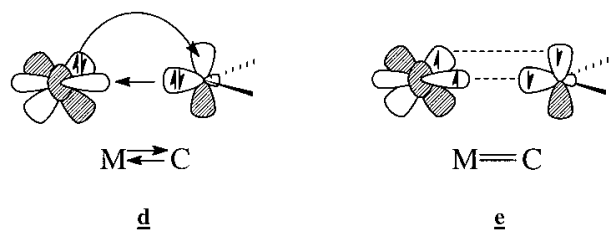

Since the work of Taylor and Hall, ${ }^{19}$ the post-Hartree-Fock calculations, ${ }^{19-23}$ such as CASSCF $^{24-26}$ (complete active space self-consistent field) and/or FORS ${ }^{27,28}$ (full optimized reaction space) methods, were undertaken to understand the bonding character of the metal carbene ${ }^{21-23}$ and the metal carbyne ${ }^{29}$ complexes. Accurate geometrical parameters, bond dissociation energies, and the rotational barrier of the carbene fragment around the $\mathrm{M}-\mathrm{C}$ bond were given in these calculations. ${ }^{20,21}$ The importance of the electronic correlation was discussed. ${ }^{21}$ Recently, density functional calculations (DFT) ${ }^{30}$ have been recognized to be a powerful computational tool in predicting the geometries and energies of transition metal complexes. ${ }^{31}$ Ziegler and co-workers ${ }^{32}$ have investigated extensively the transition metal Fischer-type complexes using the DFT approach. The relative bond energies and especially $\pi$ bond analysis of chromium-carbene, - silyene, and higher homologues were discussed ${ }^{32}$ in detail. Similar comparisons were made on the carbene complexes with transition metals of chromium triad. ${ }^{32}$ The nonlocal correction and the relativistic effects were both important for understanding the trend in bond strength, particularly the intrinsic $\pi$ bond strength. ${ }^{32}$

To characterize the nature of the Fischer-type transition metal-carbene bond, we have undertaken studies of structures, of deformation density, of the topology of the electron densities, and of the electronic structures of four pentacarbonyl chromiumcarbene complexes: $(\mathrm{CO})_{5} \mathrm{CrC}\left(\mathrm{OCH}_{3}\right)(-\mathrm{C} \equiv \mathrm{CPh}),(\mathbf{1}),(\mathrm{CO})_{5^{-}}$ $\mathrm{CrC}\left(\mathrm{NH}_{2}\right) \mathrm{Me},(2),(\mathrm{CO})_{5} \mathrm{CrC}\left(\mathrm{NH}_{2}\right) \mathrm{Ph},(3),(\mathrm{CO})_{5} \mathrm{CrC}\left(\mathrm{NMe}_{2}\right) \mathrm{Ph}$, (4). The molecular and crystal structures of all four complexes are determined by $\mathrm{X}$-ray diffraction at room temperature. The methoxy-carbene complex (1) is further investigated by X-ray diffraction at low temperature $(110 \mathrm{~K})$ in order to obtain the detailed electron density distribution experimentally. Parallel electron density distributions can be easily derived from the corresponding molecular orbital calculations. A direct comparison between the experiment and theory may shed some light on the bond characterization of this interesting system. For the 
purpose of understanding the role of the heteroatom in this type of complexes, amino carbenes are investigated as well. Unfortunately no suitable crystal of amino carbenes is available for detailed electron density study. The density distribution, bond dissociation energy, and bond characterization were made on compound 2 and simplified compound $\mathbf{1},(\mathrm{CO})_{5} \mathrm{CrC}(\mathrm{OH})-$ $(-\mathrm{C} \equiv \mathrm{CH})$. Bond characterization is analyzed through the natural bond orbital (NBO) at the HFSCF and CASSCF levels. The intrinsic $\pi$ bond will be discussed using the orbital correlation diagram and the Fermi hole distribution. In addition, the "atom in molecules" concept ${ }^{33}$ has been proven to be a feasible approach in describing chemical bonds, ${ }^{34}$ nonbonded interactions, ${ }^{35}$ and molecular ${ }^{36}$ and crystal structures. ${ }^{37}$ Therefore, bond characterization will also be presented in terms of the topological properties of the total electron density both experimentally and theoretically. Vertical ionization potentials (VIPs) are calculated with both ab initio HFSCF and DFT methods on five chromium carbenes: $2,3,4,(\mathrm{CO})_{5} \mathrm{CrC}(\mathrm{OMe})$ $\mathrm{Ph}(\mathbf{5})$, and $(\mathrm{CO})_{5} \mathrm{CrC}\left(\mathrm{NMe}_{2}\right)\left(\mathrm{CH}_{3}\right)(\mathbf{6})$. A comparison between the calculated values and the experimental PES data will be made. The theme of this work is to try to make a comparative study both on density distribution and on orbital energies.

\section{Experimental Section}

Data Collection and Refinement: Chromium Carbene Complexes. Compounds 1, 2, 3, and 4 were synthesized according to the literature procedures. ${ }^{38}$ Dark red $\mathbf{1}$ and pale yellow crystals 2,3 and $\mathbf{4}$ were obtained by using the sublimation method under vacuum. Intensities of three standard reflections of each compound were monitored every hour throughout the measurement, and no significant variation in intensity was detected in any case. Scattering factors for neutral atoms, corrected for anomalous dispersion, were taken from International Table for X-ray Crystallography, Vol. IV. ${ }^{39}$ Structures were solved by Patterson and direct methods and subsequently refined by a full matrix least-squares procedure using anisotropic thermal parameters for all non-hydrogen atoms. Relevant crystal data are listed in Table 1; details are in deposit.

Low-temperature $(110 \mathrm{~K})$ data were collected on $\mathbf{1}$ using a liquid $\mathrm{N}_{2}$ gas-flow device. Intensity data were measured up to a $2 \theta$ of $70^{\circ}$ for a full Ewald sphere, and 40 additional highangle reflections with $2 \theta^{\prime}$ s of $70-85.6^{\circ}$, which were predicted to be strong, were measured. In addition, intensities of $( \pm h$, $+k,+l)$ at four $\psi$ angles $\left(-30^{\circ},-10^{\circ}, 10^{\circ}, 30^{\circ}\right)$ were collected for each reflection up to a $2 \theta$ of $70^{\circ}$. This yielded a total of 35609 measurements, which gave 6463 unique reflections after averaging of all equivalents. An absorption correction was applied (before averaging) according to six measured faces; the correctness of the face measurements was checked against the experimental $\psi$ curves on three reflections. The interset agreement in intensities is $1.9 \%$. The counting statistic weight was applied, and the $\sigma$ of the averaged intensity was taken as a geometric mean of all the $\sigma$ 's of equivalents. To obtain all the non- $\mathrm{H}$ atom parameters of $\mathbf{1}$ for a promolecular density calculation (see below), additional high-order refinements were carried out with a $\sin \theta / \lambda$ data range from $0.65,0.70$, and 0.75 $\AA^{-1}$ with 2441,1767 , and 1008 reflections, respectively. The parameters from the refinement with $\sin \theta / \lambda \geq 0.65$ data were finally chosen for the promolecular density calculation based on the $R$ values and relevant error assessments. The hydrogen positions were displaced along the $\mathrm{C}-\mathrm{H}$ vector to make a $\mathrm{C}-\mathrm{H}$ distance of $1.08 \AA$. A multipole model refinement ${ }^{40}$ was

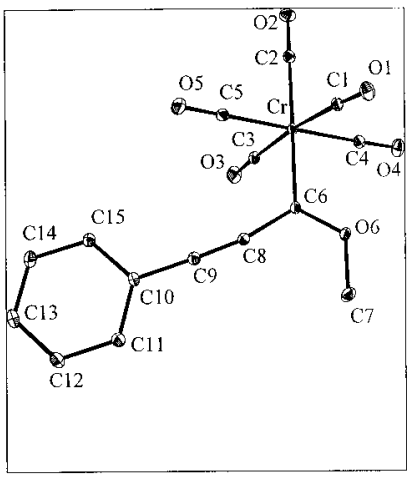

(a)

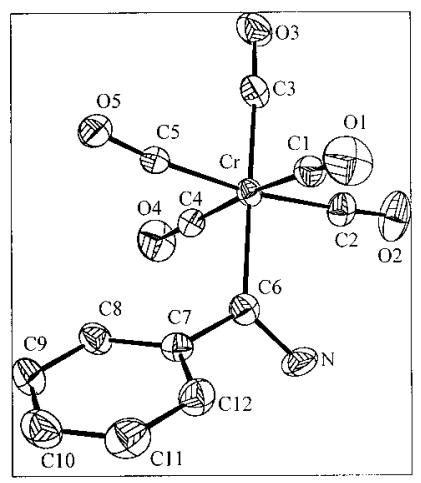

(c)

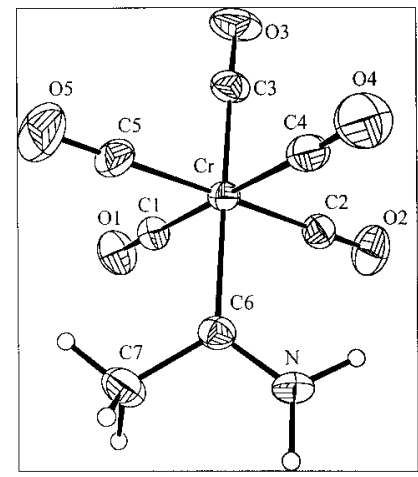

(b)

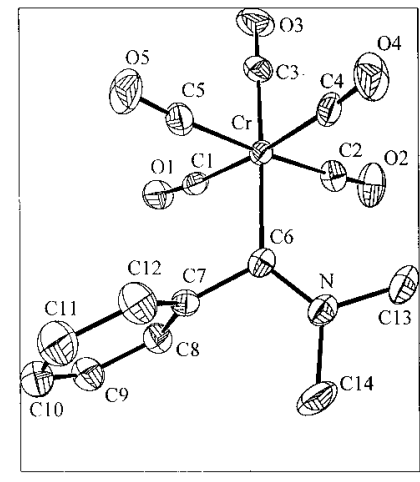

(d)
Figure 1. Molecular structure and thermal ellipsoids of compound (a) 1 at $110 \mathrm{~K}$, (b) 2, (c) 3, (d) 4 at $300 \mathrm{~K}$.

performed according to the equation.

$$
\begin{aligned}
& \rho_{\text {atomic }}(r)=\rho_{\text {core }}+P_{v} \kappa^{3} \rho_{\text {valence }}(\kappa r)+\sum_{l=0}^{l} R_{l}(r) \times \\
& \sum_{m=0, p= \pm}^{l} P_{l m p} Y_{l m p}
\end{aligned}
$$

where

$$
R_{l}(r)=\frac{\xi_{1}^{n_{l}+3}}{\left(n_{l}+2\right) !} r^{n_{l}} \exp \left(-\xi_{l} r\right)
$$

The first two terms of this equation are the spherical part of atomic electron density; the third term is the sum of multipole terms which are expressed as spherical harmonic functions $\left(Y_{l m p}\right) ; R_{l}(r)$ is the radial function; $\kappa$ is the expansion-contraction factor of the radial distribution. The $\mathrm{K}$ core is considered for the $\mathrm{Cr}$ atom; the $\mathrm{He}$ core is taken for $\mathrm{C}, \mathrm{N}$, and $\mathrm{O}$ atoms. The valence configurations of $\mathrm{Cr}, \mathrm{C}, \mathrm{N}$, and $\mathrm{O}$ atoms are $\mathrm{d}^{5}, \mathrm{~s}^{2} \mathrm{p}^{2}$, $\mathrm{s}^{2} \mathrm{p}^{3}, \mathrm{~s}^{2} \mathrm{p}^{4}$, respectively. Multipole expansions of the valence shell up to hexadecapoles for the $\mathrm{Cr}$ atom, up to octapoles for $\mathrm{C}, \mathrm{N}, \mathrm{O}$ atoms, and up to dipoles for $\mathrm{H}$ atoms are included in the refinement. Multipole coefficients, $P_{l m p}$, for $\mathrm{H}$ atoms at methyl and phenyl groups were constrained to be the same in each group; the multipole coefficients of $\mathrm{C}$ and $\mathrm{O}$ atoms of the four carbonyl groups on the equatorial plane were also constrained to be the same. The coefficients of the multipole terms together with positional and anisotropic thermal parameters were obtained by a full-matrix least-squares refinement based on $F_{\mathrm{o}}$. Atomic sacttering factors of both core and valence electrons were taken from International Tables for $X$-ray Crystallography, Vol. IV. ${ }^{39}$ Atomic parameters of compounds $\mathbf{1}, \mathbf{2}, \mathbf{3}$, and $\mathbf{4}$ are in deposit. 
TABLE 2: Agreement Indices of the Multipole Refinements on $1^{a}$

\begin{tabular}{lcccccc}
\hline & variable & $R_{1}$ & $R_{1 \mathrm{w}}$ & $R_{2}$ & $R_{2 \mathrm{w}}$ & $S$ \\
\hline conventional & 255 & 0.025 & 0.042 & 0.028 & 0.043 & 4.81 \\
monopole $_{\text {octapole }^{b}}$ & 323 & 0.025 & 0.038 & 0.025 & 0.038 & 4.21 \\
hexadecapole & 534 & 0.021 & 0.028 & 0.015 & 0.027 & 2.77 \\
& 553 & 0.021 & 0.027 & 0.015 & 0.027 & 2.71
\end{tabular}

${ }^{a} R_{2}=\sum\left|F_{\mathrm{o}}{ }^{2}-F_{\mathrm{c}}{ }^{2}\right| / \sum F_{\mathrm{o}}{ }^{2} \cdot R_{2 \mathrm{w}}=\left(\sum w\left|F_{\mathrm{o}}{ }^{2}-F_{\mathrm{c}}{ }^{2}\right|^{2} / w \sum F_{\mathrm{o}}{ }^{4}\right)^{1 / 2} \cdot{ }^{b}$ Only the $\mathrm{Cr}$ atom is up to hexadecapole.

Deformation Density. The deformation density $(\Delta \rho)$ is defined as the difference between the molecular density and the promolecular density. The promolecular density is composed of the sum of the densities from the superposition of the free spherical atoms, each centered at its equilibrium position in the molecule. The $\mathrm{X}-\mathrm{X}$ deformation density $\left(\Delta \rho_{\mathrm{X}-\mathrm{X}}\right)$ is calculated as the difference between the observed density, $\rho_{\text {obs }}$, and the superposition of the sum of spherically averaged free atomic densities; that is, the Fourier coefficients were taken to be the difference between $k F_{\mathrm{o}}$ and $F_{\mathrm{c}}$, where $F_{\mathrm{c}}$ is calculated from the parameters obtained from high-order refinement (sin $\theta / \lambda \geq 0.65 \AA^{-1}$ ) and $k$ is the optimum scale factor. Deformation density maps $\left(\Delta \rho_{\mathrm{X}-\mathrm{X}}\right)$ were calculated up to a resolution of $\sin$ $\theta / \lambda \geq 0.96 \AA^{-1}$. The model deformation density distributions $\left(\Delta \rho_{\mathrm{M}-\mathrm{A}}\right)$ were generated by subtracting the spherical atomic electron density from the sum of the atomic electron densities evaluated from a multipole model. ${ }^{40}$ The coefficients $\left(P_{\nu}, P_{l m p}\right)$ of the multipole terms are obtained from a least-squares fit of the X-ray diffraction data using the MOLLY program. ${ }^{40 \mathrm{a}, \mathrm{b}}$ The static multipole deformation densities $\left(\Delta \rho_{\mathrm{M}-\mathrm{A} \text {,static }}\right)$ were calculated in direct space according to the equation given above. ${ }^{40 \mathrm{c}}$ The residual density, $\Delta \rho_{\text {res }}$, is defined as the difference between the observed and the multipole model ones.

Topology of Electron Density. The total electron density distribution, $\rho(r)$, is calculated using the multipole model. The gradient vector field, $\nabla \rho(r)$, and Laplacian, $\nabla^{2} \rho(r)$, are derived according to the logarithms given by Bader. ${ }^{33}$ Bond critical points $\left(r_{\mathrm{c}}\right)$ are located at each chemical bond, where associated properties, ${ }^{33}$ such as the density, $\rho\left(r_{\mathrm{c}}\right)$, and the Laplacian, $\nabla^{2} \rho$ $\left(r_{\mathrm{c}}\right)$, values at the bond critical point, bond ellipticity, $\epsilon$, etc., are used to characterize the bond type and bond order. Bond path and atomic domain can also be obtained.

All computations were carried out on Micro VAX and IBM Risc 6000 computers using NRCVAX,,${ }^{41}$ MOLLY,,${ }^{40, b}$ SALLY, ${ }^{40 c}$ and $\mathrm{PROP}^{42}$ programs. The contours of model deformation density were produced by a locally developed contour-plotting program. ${ }^{43}$

\section{Molecular Orbital Calculations}

Geometry and Basis Functions. To compare bonding between the amino- and alkoxy-chromium-Fischer carbenes,

TABLE 3: Comparisons of Selected Bond Lengths of Some Chromium-Fischer Carbene Complexes

\begin{tabular}{|c|c|c|c|c|c|c|}
\hline$(\mathrm{CO})_{5} \mathrm{CrC}\left(\mathrm{XR}^{\prime}\right) \mathrm{R}$ & $\mathrm{Cr}-\mathrm{C}_{\text {carbene }}$ & $\mathrm{X}-\mathrm{C}_{\text {carbene }}$ & $\mathrm{Cr}-\mathrm{C}_{\text {cis }}$ (av) & $\mathrm{Cr}-\mathrm{C}_{\text {trans }}$ & $\phi$ & ref \\
\hline $\begin{array}{l}\mathrm{XR}^{\prime}=\mathrm{OMe}(\mathbf{1}) \\
\mathrm{R}=-(\mathrm{C} \equiv \mathrm{CPh})\end{array}$ & $1.9990(4)$ & $1.3233(4)$ & 1.894 & 1.897 & 31 & $a$ \\
\hline $\begin{array}{l}\mathrm{XR}=\mathrm{OEt} \\
\mathrm{R}=-(\mathrm{C} \equiv \mathrm{CPh})\end{array}$ & $2.00(2)$ & $1.32(2)$ & & & & 68 \\
\hline $\begin{array}{l}\mathrm{XR}^{\prime}=\mathrm{OMe} \\
\mathrm{R}=\mathrm{Ph}\end{array}$ & $2.04(3)$ & $1.33(2)$ & 1.89 & 1.87 & & 69 \\
\hline $\begin{array}{l}\mathrm{XR}^{\prime}=\mathrm{OEt} \\
\mathrm{R}=\mathrm{Me}\end{array}$ & $2.053(1)$ & $1.314(1)$ & 1.908 & 1.893 & 45 & 70 \\
\hline $\begin{array}{l}\mathrm{XR}^{\prime}=\mathrm{OMe} \\
\mathrm{R}=\mathrm{CH}(\mathrm{Me})(\mathrm{Et})\end{array}$ & 2.006 & 1.301 & 1.873 & 1.899 & 10 & 71 \\
\hline $\begin{array}{l}\mathrm{XR}^{\prime}=\mathrm{OEt} \\
\mathrm{R}=\mathrm{C}(\mathrm{OMe})(\mathrm{CHOMe})\end{array}$ & 2.061 & 1.336 & 1.905 & 1.883 & 44 & 72 \\
\hline $\begin{array}{l}\mathrm{XR}^{\prime}=\mathrm{OH} \\
\mathrm{R}=\mathrm{Ph}\end{array}$ & 2.052 & 1.316 & 1.908 & 1.866 & 37 & 73 \\
\hline $\begin{array}{l}\text { anion: } \mathrm{BF}_{4}^{-}, \mathrm{XR}^{\prime}=\mathrm{OEt} \\
\mathrm{R}=\mathrm{CH}_{2}\left[\mathrm{NC}_{6} \mathrm{H}_{8}\left(\mathrm{CH}_{3}\right)\right]\end{array}$ & 2.02 & 1.306 & 1.899 & 1.885 & 39 & 74 \\
\hline $\begin{array}{l}\text { cation: } \mathrm{NMe}_{4}^{+}, \mathrm{X}=\mathrm{O} \\
\mathrm{R}=\mathrm{C}(\mathrm{Me})\left(\mathrm{CH}_{2}\right)\end{array}$ & $2.147(5)$ & $1.232(6)$ & 1.884 & 1.838 & 45 & 75 \\
\hline $\begin{array}{l}\mathrm{XR}=\mathrm{NH}_{2}(\mathbf{2}) \\
\mathrm{R}=\mathrm{Me}\end{array}$ & $2.081(4)$ & $1.293(6)$ & 1.884 & 1.856 & 37 & $a$ \\
\hline $\begin{array}{l}\mathrm{XR}^{\prime}=\mathrm{NMe}_{2}(\mathbf{3}) \\
\mathrm{R}=\mathrm{Ph}\end{array}$ & $2.097(7)$ & $1.334(8)$ & 1.889 & 1.835 & 42 & $a$ \\
\hline $\begin{array}{l}\mathrm{XR}^{\prime}=\mathrm{NH}_{2}(\mathbf{4}) \\
\mathrm{R}=\mathrm{Ph}\end{array}$ & $2.057(6)$ & $1.313(8)$ & 1.882 & 1.853 & 2 & $a$ \\
\hline $\begin{array}{l}\mathrm{XR}^{\prime}=\mathrm{NH}(\mathrm{Me}) \\
\mathrm{R}=\mathrm{Me}\end{array}$ & 2.09 & 1.33 & 1.87 & 1.81 & & 76 \\
\hline $\begin{array}{l}\mathrm{XR}^{\prime}=\mathrm{NEt}_{2} \\
\mathrm{R}=\mathrm{Me}\end{array}$ & $2.16(1)$ & $1.31(1)$ & 1.90 & 1.85 & & 77 \\
\hline $\begin{array}{l}\mathrm{XR}^{\prime}=\mathrm{N}\left(\mathrm{C}_{4} \mathrm{H}_{6}\right) \\
\mathrm{R}=\mathrm{Me}\end{array}$ & $2.123(2)$ & $1.300(2)$ & 1.89 & 1.86 & & 78 \\
\hline $\begin{array}{l}\mathrm{XR}^{\prime}=\mathrm{N}(\mathrm{Me})(i-\mathrm{Pr}) \\
\mathrm{R}=\mathrm{Me}\end{array}$ & 2.116 & 1.278 & 1.888 & 1.898 & 43 & 79 \\
\hline $\begin{array}{l}\mathrm{XR}^{\prime}=\mathrm{NMe}\left(\mathrm{CH}_{2} \mathrm{Ph}\right) \\
\mathrm{R}=\mathrm{Me}\end{array}$ & 2.135 & 1.309 & 1.892 & 1.858 & 38 & 80 \\
\hline $\begin{array}{l}\mathrm{XR}^{\prime}=\mathrm{NC}_{5} \mathrm{H}_{80} \\
\mathrm{R}=\mathrm{C}_{5} \mathrm{H}_{6}\end{array}$ & 2.125 & 1.317 & 1.896 & 1.853 & 45 & 81 \\
\hline $\begin{array}{l}\mathrm{XR}^{\prime}=\mathrm{NC}(\mathrm{OMe}) \mathrm{Ph} \\
\mathrm{R}=\mathrm{CMe}_{3}\end{array}$ & 2.148 & 1.268 & 1.903 & 1.876 & 9 & 82 \\
\hline $\begin{array}{l}\mathrm{XR}^{\prime}=\mathrm{N}\left(\mathrm{C}_{6} \mathrm{H}_{11}\right) \\
\mathrm{R}=\mathrm{C}\left(\mathrm{CH}_{2}\right)(\mathrm{OMe})\end{array}$ & $2.15(1)$ & $1.32(2)$ & 1.875 & $1.88(2)$ & 47 & 83 \\
\hline Calc $\mathrm{Cr}-\mathrm{C}\left(\mathrm{sp}^{2}\right)$ & 2.21 & $\begin{array}{l}\mathrm{C}=\mathrm{O}=1.22 \\
\mathrm{C}=\mathrm{N}=1.28\end{array}$ & & & & 84 \\
\hline
\end{tabular}

${ }^{a}$ This work. 


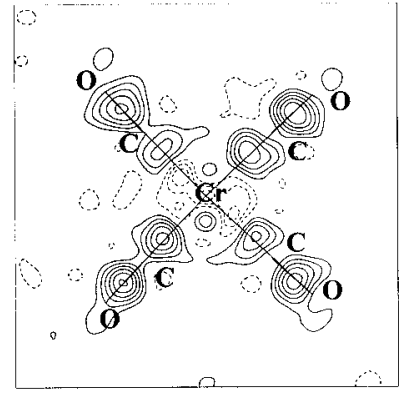

(a)

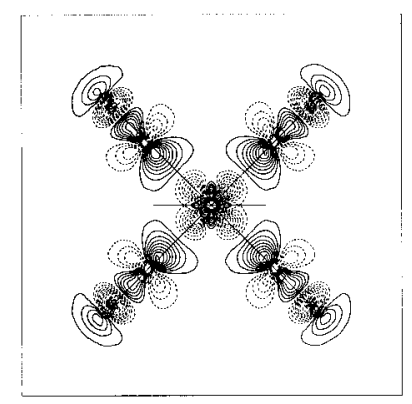

(c)

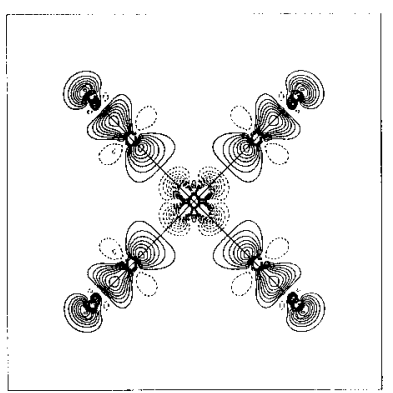

(e)

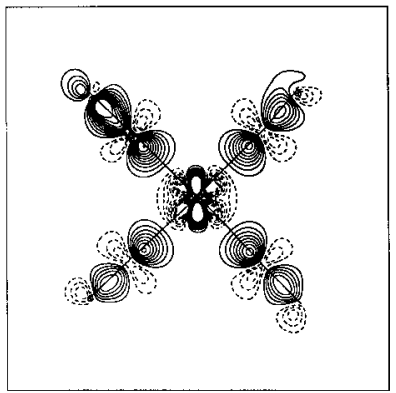

(b)

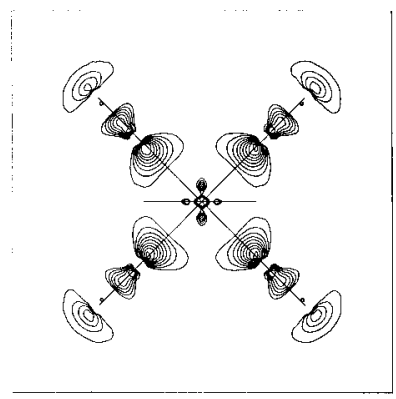

(d)

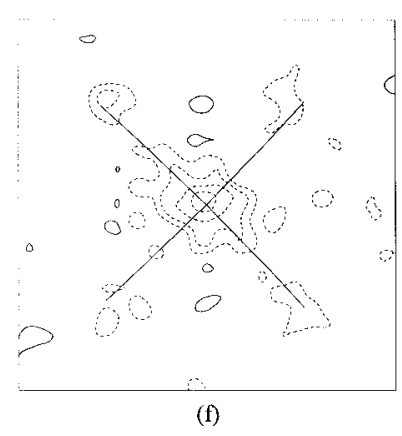

Figure 2. Deformation density distribution on the equatorial $\mathrm{Cr}(\mathrm{CO})_{4}$ plane for compound 1: solid line positive, dotted line negative, contour

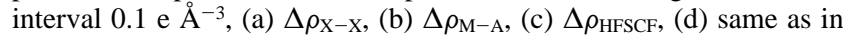
c, but with positive contours only, (e) $\Delta \rho_{\text {DFT }}$, (f) $\Delta \rho_{\text {residual }}$.

compound 2 and simplified compound $1(\mathrm{CO})_{5} \mathrm{CrC}(\mathrm{OH})$ $(\mathrm{C} \equiv \mathrm{CH})$ are chosen for the $\mathrm{MO}$ calculations. The molecular geometries are basically taken from the diffraction work and are defined to have $C_{s}$ symmetry. All the $\mathrm{Cr}-\mathrm{C}_{\text {carbonyl }}$ distances of model compound $\mathbf{1}$ were considered to be equal, with an average bond length of $1.894 \AA$. The carbene plane is at the bisection of the $\mathrm{C}-\mathrm{Cr}-\mathrm{C}$ angle to ensure $C_{s}$ symmetry. For compound 2, four $\mathrm{Cr}-\mathrm{C}_{\text {carbonyl,cis }}$ were set to be equal at the average bond length of $1.884 \AA$, and the $\mathrm{Cr}-\mathrm{C}_{\text {carbonyl,trans }}$ bond length was taken at $1.857 \AA$; again the carbene plane is at the bisection of the $\mathrm{C}-\mathrm{Cr}-\mathrm{C}$ angle. The $\mathrm{Cr}(\mathrm{CO})_{5}$ fragments of both compounds are assumed to be in $C_{4 v}$ symmetry. The internal coordinate at the $\mathrm{Cr}$ atom is defined in the same way for both carbenes, where the $z$-axis is along the $\mathrm{Cr}-\mathrm{C}_{\text {carbene }}$ and the $x z$-plane is at the mirror plane $\left(C_{s}\right)$. The basis set used for the $\mathrm{Cr}$ atom is $(14,9,6) /[8,4,3]$ contractions, i.e., $(626 * 1 / 5112 /$ $411),{ }^{44,45}$ where $14 \mathrm{~s}, 9 \mathrm{p}$ primitive Gaussian functions are taken from Wachter ${ }^{44}$ and $6 \mathrm{~d}$ functions are taken from Goddard. ${ }^{45}$ The basis sets used for $\mathrm{N}, \mathrm{O}, \mathrm{C}$, and $\mathrm{H}$ atoms are taken from split valence level double- $\zeta 6-31 \mathrm{G}$. The basis used in the DFT calculations is a double numerical basis set augmented by polarization functions (DNP). ${ }^{46 a, b}$ Electron correlation is treated within the local density approximation (LDA) in the parameterization of Vosko et al. ${ }^{47}$ The bond dissociation energies are determined by adding Becke' $\mathrm{s}^{48}$ nonlocal exchange correc-

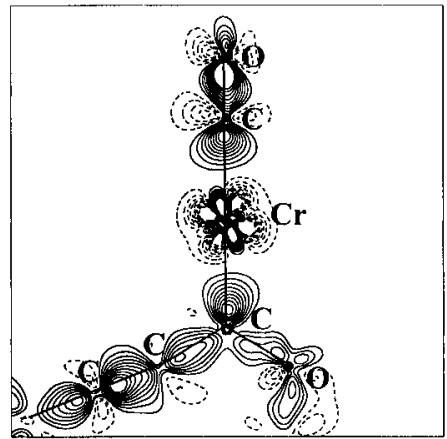

(a)

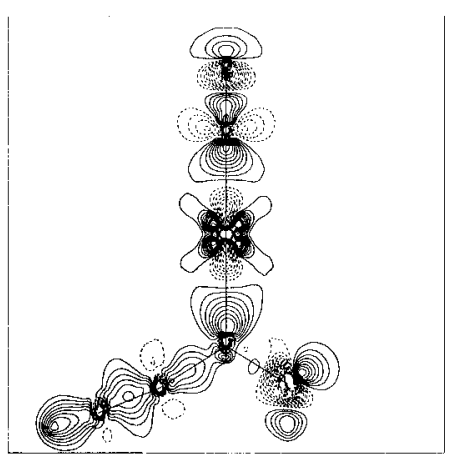

(b)

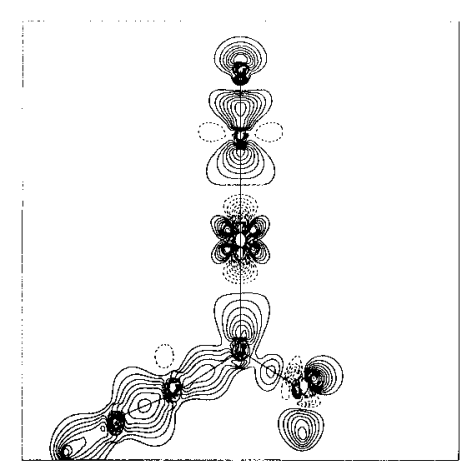

(c)

Figure 3. Deformation density distribution on the plane of $\mathrm{Cr}-\mathrm{C} 6-$ O6 for compound 1: (a) $\Delta \rho_{\mathrm{M}-\mathrm{A}}$, (b) $\Delta \rho_{\mathrm{HFSCF}}$, (c) $\Delta \rho_{\mathrm{DFT}}$; contours are as in Figure 2.

tions as well as Perdew's ${ }^{49}$ inhomogeneous gradient corrections for correlation (LDA/NL/BP) as a perturbation.

HFSCF and CASSCF Calculations. The CASSCF (complete active space self-consistent field $)^{24-26}$ is a limited type of multiconfiguration self-consistent field (MCSCF) calculation which provides an optimized sets of primary orbitals for configuration interaction (CI) calculations. A Hartree-Fock calculation (HFSCF) is performed on model compounds $\mathbf{1}$ and $\mathbf{2}$, and the molecular orbitals are assigned accordingly (the $\mathrm{A}^{\prime}$ state configurations between two compounds are similar to $\pi_{2}^{2} \sigma^{2} \mathrm{~d}_{x z}^{2} \mathrm{~d}_{x^{2}-y^{2}}^{2} \pi_{1}^{2}$, where $\pi_{1}$ denotes the $\mathrm{Cr}-\mathrm{C}_{\text {carbene }} \pi$ bond, $\pi_{2}$ denotes the $\pi$ bond of $\left.C_{\text {carbene }}-X ; X=O, N\right)$. Six orbitals concerning the $\pi_{\mathrm{C}-\mathrm{X}}, \sigma_{\mathrm{Cr}-\mathrm{C}}, \pi_{\mathrm{Cr}-\mathrm{C}}, \pi^{*}{ }_{\mathrm{Cr}-\mathrm{C}}, \sigma^{*}{ }_{\mathrm{Cr}-\mathrm{C}}, \pi^{*}{ }_{\mathrm{C}-\mathrm{X}}$ orbitals of the $\mathrm{Cr}-\mathrm{C}_{\text {carbene }}$ double bond are chosen to be the active space, i.e., three occupied orbitals $\left(\pi_{1}, \sigma, \pi_{2}\right)$ and three unoccupied orbitals $\left(\pi^{*}, \sigma^{*}, \pi^{*}\right)$ for $\mathrm{Cr}=\mathrm{C}$ region. A configuration interaction calculation within the framework of these six orbitals optimized by the $\operatorname{CASSCF}(6,6)$ method with 175 spin-adapted configurations is performed on both $\mathbf{1}$ and 2 . An additional $\operatorname{CASSCF}(6,6)$ calculation is applied to both compounds 1 and 2 with the $(\mathrm{CO})_{5} \mathrm{Cr}$ and carbene fragments 


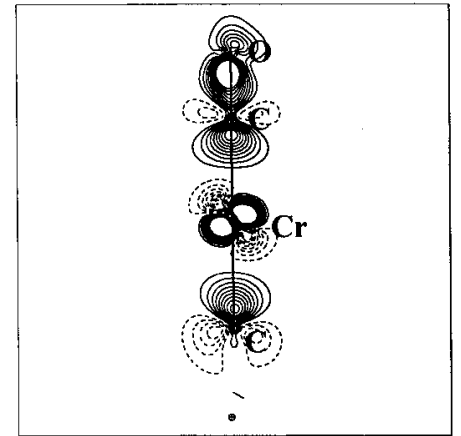

(a)

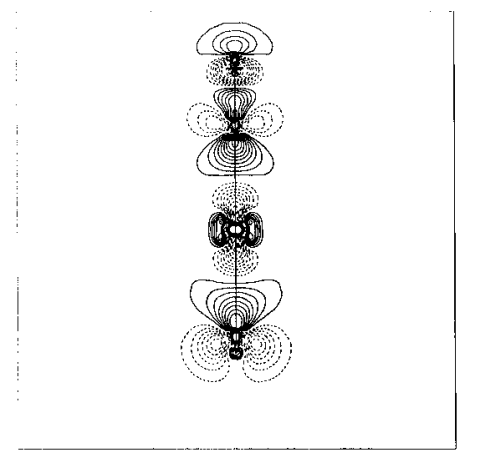

(b)

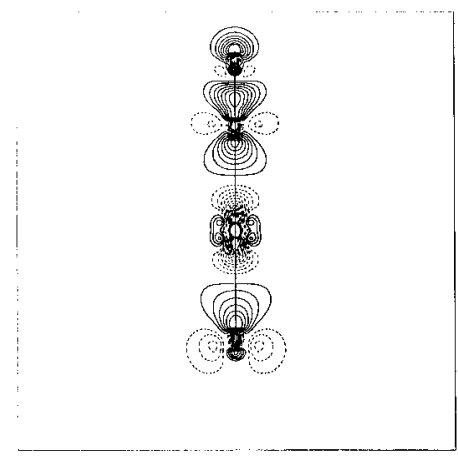

(c)

Figure 4. Deformation density distribution on the plane perpendicular to Figure 3 and through the $\mathrm{Cr}-\mathrm{C}_{\text {carbene }}$ bond of compound 1: (a) $\Delta \rho_{\mathrm{M}-\mathrm{A}}$, (b) $\Delta \rho_{\mathrm{HFSCF}}$, (c) $\Delta \rho_{\mathrm{DFT}}$, contours are as in Figure 2.

separated by $6 \AA$ in order to obtain the orbital correlation and bond dissociation energy.

Natural Bond Orbital Analysis. Natural bond orbital analysis ${ }^{50-54}$ comprises a sequence of transformations from the given basis sets to various localized sets: natural atomic orbitals (NAOs), natural hybrid orbitals (NHOs) ${ }^{51}$ natural bond orbitals ${ }^{53}$ (NBOs), and natural localized molecular orbitals (NLMOs). ${ }^{50,52}$ The given basis functions are taken from ab initio $\mathrm{HF}$ and CASSCF calculations. The results after NBO analysis are generally in good agreement with Lewis structure concepts and the Pauling-Slater-Coulson ${ }^{55}$ concept of bond hybridization and polarization. Net atomic charges, orbital populations, and bond orders are thus generated by means of an NBO analysis. The charges and orbital populations obtained this way are designed as the natural orbital population analysis (NPA), which is compared with the Mulliken population analysis (MPA). In DFT calculations, a Hirshfeld partition ${ }^{46 c}$ is used for obtaining the net atomic charge.

Theoretical Deformation Density. The theoretical deformation density $\left(\Delta \rho_{\text {theo }}\right)$ is defined as the difference between the total molecular density and the promolecular electron density. The total molecular density is calculated from HFSCF molecular

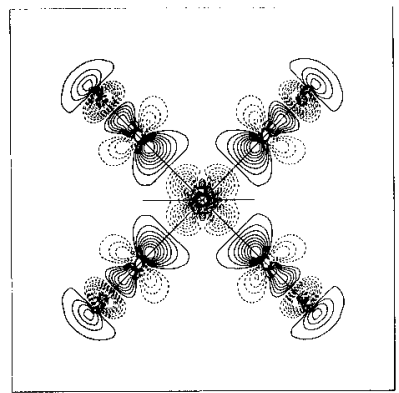

(a)

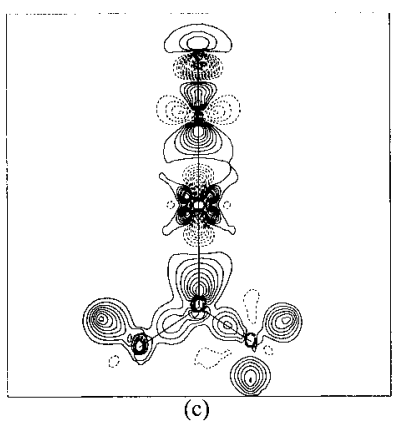

(c)

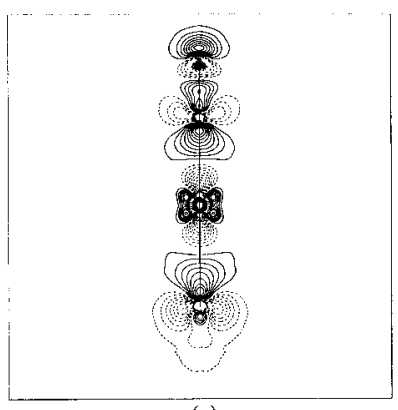

(e)

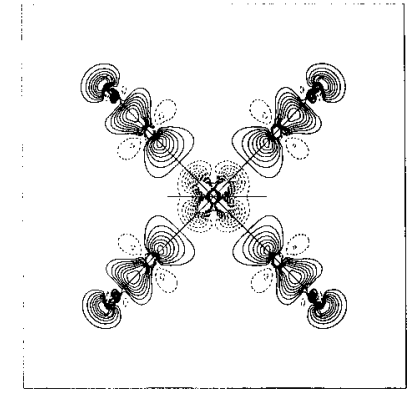

(b)

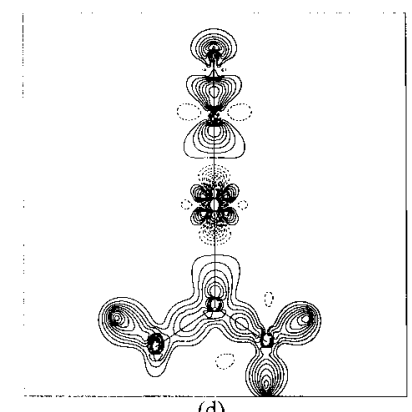

(d)

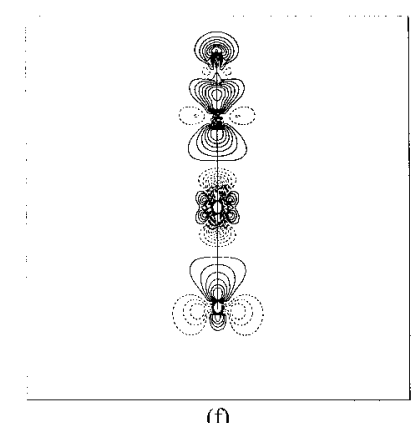

(f)
Figure 5. Deformation density distribution of compound 2 on the three planes as defined in Figure 2, Figure 3, and Figure 4 for (a, b), (c, d) and $(\mathrm{e}, \mathrm{f})$ respectively. Contours are as in Figure 2; (a, c, and e) from HFSCF calculation; (b, d, and f) from DFT calculation.

wave functions; each occupied molecular orbital is assigned to have two electrons. The promolecular electron density is the sum of superposition of the spherical atomic density with atoms at the same nuclear positions as in the molecular geometry. The spherical atomic density is calculated at the ROHF/GVB level. ${ }^{56}$ The total molecular electron density is used for the gradient vector field, $\nabla \rho(r)$, and the Laplacian distribution. Bond critical points are located, and the associated properties are derived. The Fermi hole function ${ }^{57-59}$ is a measure of Pauli exculsion and is utilized here for characterizing the electron delocalization.

Ionization Potentials. Vertical ionization potentials (VIPs) are obtained on the basis of Koopmann's theory ${ }^{60}$ using ab initio calculation (HFSCF). IPs from DFT are calculated on the basis of a simple approximation to Slater's transition-state concept ${ }^{61}$ originated from Åsbrink et al., ${ }^{62}$ where instead of removing half of an electron from the MO of interest, we remove half of an electron evenly from the top ten valence MOs. ${ }^{63}$

All computations are performed on CONVEX C3840 and Power Challenge computers using the Gaussian $94^{64}$ and DMol programs. ${ }^{65}$ The MOPLOT ${ }^{66}$ program is used for the deformation density calculation. The AIMPAC ${ }^{67}$ program is used for topological analysis.

\section{Results and Discussions}

Structure. The molecular structures of 1, 2, 3, and 4 are depicted in Figure 1. The agreement indices at various stages 
TABLE 4: d Orbital Populations of Cr Atom in (a) 1; (b) $2^{a}$

\begin{tabular}{|c|c|c|c|c|c|c|}
\hline \multirow[b]{2}{*}{ (a) } & \multicolumn{2}{|c|}{ HFSCF } & \multicolumn{2}{|c|}{$\operatorname{CASSCF}(6,6)$} & \multirow[b]{2}{*}{ DFT MPA } & \multirow[b]{2}{*}{ multipole } \\
\hline & MPA & NPA & MPA & NPA & & \\
\hline $\mathrm{d}_{x y}$ & $0.55(9 \%)$ & $0.89(13 \%)$ & $0.55(10 \%)$ & $0.89(13 \%)$ & $0.72(13 \%)$ & $0.56(14 \%)$ \\
\hline $\mathrm{d}_{z^{2}}$ & $0.52(9 \%)$ & $0.87(13 \%)$ & $0.52(9 \%)$ & $0.87(13 \%)$ & $0.79(15 \%)$ & $0.83(21 \%)$ \\
\hline $\mathrm{d}_{y z}$ & $1.47(25 \%)$ & $1.58(23 \%)$ & $1.45(25 \%)$ & $1.59(23 \%)$ & $1.34(25 \%)$ & $0.95(24 \%)$ \\
\hline $\mathrm{d}_{x z}$ & $1.72(30 \%)$ & $1.81(26 \%)$ & $1.71(30 \%)$ & $1.80(26 \%)$ & $1.20(22 \%)$ & $0.61(15 \%)$ \\
\hline $\mathrm{d}_{x^{2}-y^{2}}$ & $1.58(27 \%)$ & $1.69(25 \%)$ & $1.52(26 \%)$ & $1.66(25 \%)$ & $1.38(25 \%)$ & $1.03(26 \%)$ \\
\hline total & 5.84 & 6.84 & 5.75 & 6.81 & 5.43 & 3.98 \\
\hline (b) & MPA & NPA & \multicolumn{2}{|c|}{ MPA } & NPA & MPA \\
\hline $\mathrm{d}_{x y}$ & $0.55(9 \%)$ & $0.90(13 \%)$ & \multicolumn{2}{|c|}{$0.55(9 \%)$} & $0.88(13 \%)$ & $0.72(13 \%)$ \\
\hline $\mathrm{d}_{z^{2}}$ & $0.55(9 \%)$ & \multirow{2}{*}{$\begin{array}{l}0.88(13 \%) \\
1.67(24 \%)\end{array}$} & \multicolumn{2}{|c|}{$0.55(9 \%)$} & $0.90(13 \%)$ & $0.78(14 \%)$ \\
\hline $\mathrm{d}_{y z}$ & $1.55(26 \%)$ & & \multicolumn{2}{|c|}{$1.49(26 \%)$} & $1.65(24 \%)$ & $1.37(25 \%)$ \\
\hline $\mathrm{d}_{x z}$ & $1.69(30 \%)$ & $\begin{array}{l}1.67(24 \%) \\
1.77(26 \%)\end{array}$ & \multicolumn{2}{|c|}{$1.71(30 \%)$} & $1.76(26 \%)$ & $1.31(24 \%)$ \\
\hline $\mathrm{d}_{x^{2}-y^{2}}$ & \multirow{2}{*}{$\begin{array}{l}1.54(26 \%) \\
5.88\end{array}$} & $1.65(24 \%)$ & & & $1.65(24 \%)$ & $1.28(24 \%)$ \\
\hline total & & 6.87 & \multicolumn{2}{|c|}{5.82} & 6.84 & 5.46 \\
\hline
\end{tabular}

${ }^{a}$ MPA: Mulliken population analysis. NPA: Natural orbital population analysis.

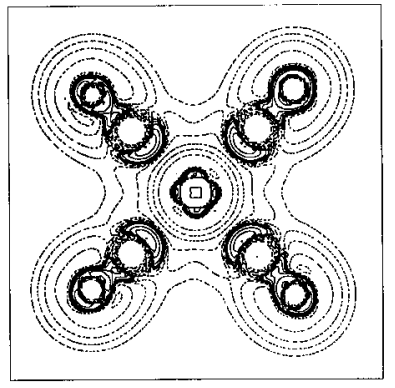

(a)

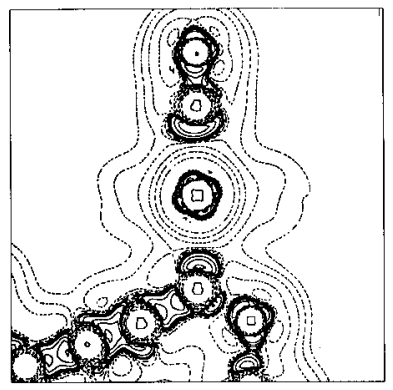

(c)

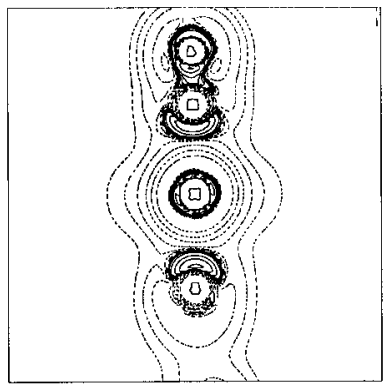

(e)

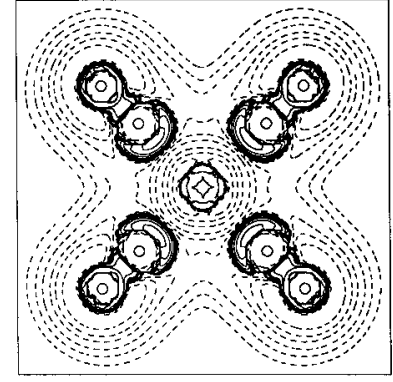

(b)

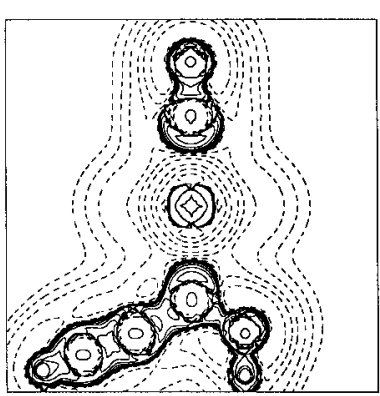

(d)

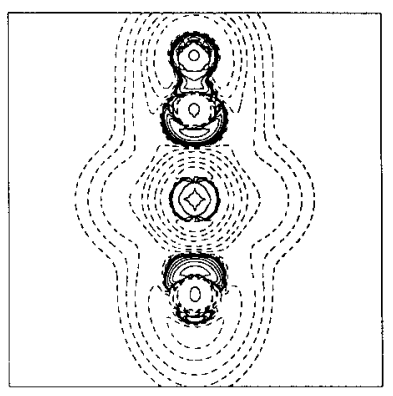

(f)

Figure 6. Negative Laplacian of electron density, $-\nabla^{2} \rho(r)$, of compound 1. Solid lines are in regions where electronic charge is concentrated, and dashed lines are in regions where charge is depleted; (a, c, and e) obtained from experiment; (b, d, and f) from theory. Plane definitions are given in Figures 2, 3, and 4. Contour intervals, $\pm 2^{i} \times 10^{j}$ $\mathrm{e} \AA^{-5} ; i=1,2,3$ and $j=-1,0,1$. Box size $8 \times 8 \AA$.

of multipole refinement on $\mathbf{1}$ are given in Table 2. The apparent improvement is observed by going up to octapole, where only the $\mathrm{Cr}$ atom is modeled to hexadecapole; additional hexadecapole terms for other atoms do not improve the model significantly. It is well-known that in Fischer carbene complexes, the heteroatom $(X=N, O$, and $S)$ stabilizes the carbene complex by its electron pair donation to the carbene carbon atom. The

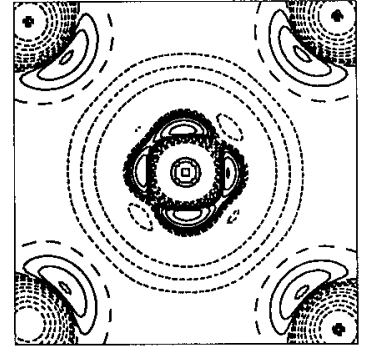

(a)

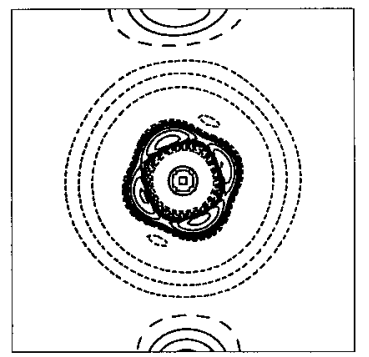

(c)

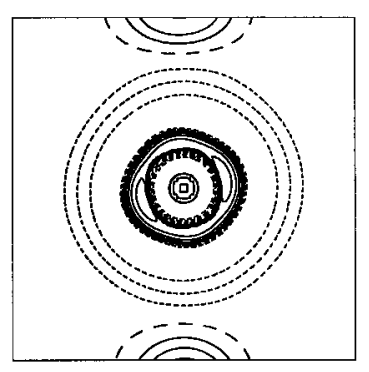

(e)

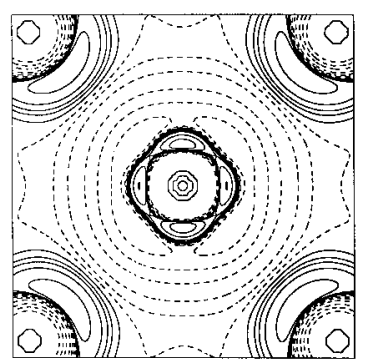

(b)

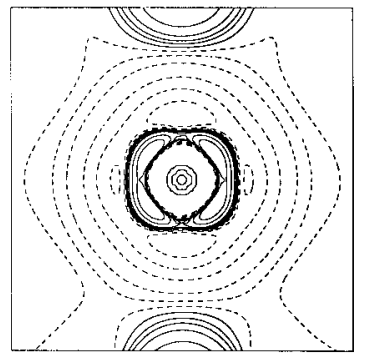

(d)

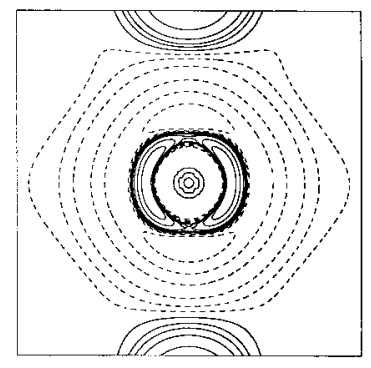

(f)
Figure 7. Negative Laplacian around $\mathrm{Cr}$ of $\mathbf{1}$. Definitions of a-f are as those in Figure 6. Contour intervals, $\pm 2^{i} \times 10^{j}$ e $\AA^{-5} ; i=1,2,3$ and $j=0,1,2,3$. Box size $3 \times 3 \AA$.

resulting partial double-bond character between the heteroatom and the carbene carbon is manifested by a shortening of the carbon-heteroatom bond, $\mathrm{C}-\mathrm{X}$. The $\mathrm{Cr}-\mathrm{C}_{\text {carbene }}, \mathrm{C}_{\text {carbene- }} \mathrm{X}$ bond lengths on a collection of chromium-carbene complexes with $\mathrm{X}=\mathrm{O}, \mathrm{N}$ are listed in Table 3 . In general, the $\mathrm{Cr}-\mathrm{C}_{\text {carbene }}$ bond is significantly shorter than the predicted $\mathrm{Cr}-\mathrm{C}_{\mathrm{sp}^{2}}$ single bond, ${ }^{84}$ but it is $\sim 0.1 \AA$ longer in amino carbene $(\mathrm{X}=\mathrm{N})$ than that in alkoxy carbene $(\mathrm{X}=\mathrm{O})$. This finding is reproduced in a recent theoretical calculation. ${ }^{85}$ The $\mathrm{C}-\mathrm{X}$ bond lengths are all longer than the expected $\mathrm{C}=\mathrm{O}$ and $\mathrm{C}=\mathrm{N}$ double-bond lengths. One exception is the carbene anion, $\left[\mathrm{NMe}_{4}\right]\left[(\mathrm{CO})_{5^{-}}\right.$ $\left.\mathrm{CrC}(\mathrm{O}) \mathrm{CMeCH}_{2}\right],{ }^{75}$ where $\mathrm{C}-\mathrm{X}(1.232 \AA)$ is apparently a 
localized double bond and the corresponding $\mathrm{Cr}-\mathrm{C}(2.147 \AA)$ is the longest among the alkoxy carbenes. The inverse relationships between $\mathrm{C}-\mathrm{X}$ and $\mathrm{Cr}-\mathrm{C}_{\text {carbene }}$ bond lengths in Fischer carbene complexes are well established ${ }^{74}$ this evidence is consistent with the "competition" between acyl (or imino) and carbene forms. The $\mathrm{Cr}-\mathrm{C}_{\text {carbonyl }}$ bond in these complexes is, on the average, 1.89-1.90 $\AA$. However, in amino carbene, such a bond at the trans position (with respect to carbene) is usually $0.03-0.05 \AA$ shorter than those at the cis position; the corresponding carbonyl bond $(\mathrm{C} \equiv \mathrm{O})$ is somewhat longer $(1.152$ vs $1.135 \AA$ ). This indicates that the $\pi$ bond character is extended to the trans $\mathrm{Cr}-\mathrm{C}_{\text {carbonyl }}$ bond more prominently in the case of $\mathrm{X}=\mathrm{N}$ than in the case of $\mathrm{X}=\mathrm{O}$. This is also found ${ }^{85}$ in the calculated BDE, the BDE of trans $\mathrm{Cr}-\mathrm{C}_{\text {carbonyl }}$ being $\sim 15 \mathrm{KJ} /$ mol higher in an amino carbene, $(\mathrm{CO})_{5} \mathrm{Cr}\left(\mathrm{NH}_{2}\right) \mathrm{R}$, than in an alkoxy one. The coordination sphere of $\mathrm{Cr}$ is roughly tetragonal distorted $O_{h}$, with the plane of carbene fragment making an angle of $\phi$ with respect to one of the cis $\mathrm{Cr}-\mathrm{C}_{\text {carbonyl }}$ axes. The angle $(\phi)$ is mostly in the range $30-45^{\circ}$; however, in three cases they are less than $10^{\circ}$ (Table 3 ). Therefore the commonly observed conformation is with the carbene fragment plane close to the bisection of $\angle \mathrm{C}_{\text {carbonyl }}-\mathrm{Cr}-\mathrm{C}_{\text {carbonyl }}$, i.e., at $\phi$ of $45^{\circ}$.

Deformation Density Maps. Deformation density maps on the equatorial $\mathrm{Cr}(\mathrm{CO})_{4}$ plane are displayed in Figure 2 in terms of $\Delta \rho_{\mathrm{X}-\mathrm{X}}, \Delta \rho_{\mathrm{M}-\mathrm{A}}, \Delta \rho_{\mathrm{M}-\mathrm{A}, \text { statics}}, \Delta \rho_{\text {res }}$, and the corresponding calculated maps generated by ab initio and DFT calculations. The features on the $\mathrm{Cr}-\mathrm{C}_{\text {carbonyl }}$ and $\mathrm{C} \equiv \mathrm{O}$ regions are as expected. It clearly shows the $\sigma$ donor characteristics of the carbonyl carbon. The accumulation of density along the $\mathrm{C} \equiv \mathrm{O}$ carbonyl bond is apparent. The agreement between experimental deformation density maps ( $\mathrm{a}$ and $\mathrm{b}$ ) and theoretical ones (c and e) are excellent at these regions. The lone pair electron density of the oxygen atom shown in the theoretical map (Figure $2 \mathrm{c}, \mathrm{e}$ ) is not observable in experimental maps (Figure 2a) and only slightly observable in the static model density map (Figure $2 b)$. This is probably due to the limited range of data measurements and unavoidable thermal smearing effect in the experimental data. However, near the $\mathrm{Cr}$ nucleus, there is a significant difference between $\mathrm{b}$ and $\mathrm{c}$ in Figure 2. The asymmetric distribution around the $\mathrm{Cr}$ atom in $\Delta \rho_{\mathrm{X}-\mathrm{X}}, \Delta \rho_{\mathrm{M}-\mathrm{A}}$, is quite pronounced; that is, there is positive deformation density along the direction at the bisection of $\angle \mathrm{C} 4-\mathrm{Cr}-\mathrm{C} 3$ (or $\angle \mathrm{C} 5-$ $\mathrm{Cr}-\mathrm{C} 1$ ), but no accumulation is observed along the direction at the bisection of $\angle \mathrm{C} 4-\mathrm{Cr}-\mathrm{C} 1$ (or $\angle \mathrm{C} 3-\mathrm{Cr}-\mathrm{C} 5$ ). It is worth mentioning that this direction (bisection of $\angle \mathrm{C} 4-\mathrm{Cr}-\mathrm{C} 1$ ) is the plane of the carbene fragment. This is not expected on the basis of the simple crystal field theory around $\mathrm{Cr}$. If we take a close look at the corresponding theoretical maps, the asymmetric distribution does exist near the $\mathrm{Cr}$ (Figure 2c) as well. To clarify this feature, a plot showing the positive contour only is given in Figure 2d, where it is clear that the positive deformation density is significantly more in one direction (bisection of $\angle \mathrm{C} 4-\mathrm{Cr}-\mathrm{C} 1$ ) than the other. Such asymmetric distribution is similar to that observed in Figure 2b. A similar observation is made in the DFT calculation (Figure 2e). Obviously, the plane of the carbene fragment does play a certain role in such asymmetric density distribution around the $\mathrm{Cr}$ atom. The residual density in Figure $2 \mathrm{f}$ simply demonstrates the validity of the multipole model. The deformation density maps of the carbene plane and the plane perpendicular to it are shown in Figure 3 and 4, respectively. Other than the asymmetric distribution near $\mathrm{Cr}$, all the features are in very good agreement between experiment (Figure 3a, 4a) and theory (Figure 3b,c, $4 \mathrm{~b}, \mathrm{c}$ ); for example, the features along the $\mathrm{Cr}-\mathrm{C} 6, \mathrm{C} 6-\mathrm{C} 8$ bonds and the $\mathrm{C} 8-\mathrm{C} 9$ triple bond agree very well with each other.
TABLE 5: Charges of Fragments of (a) 1; (b) $2^{a}$

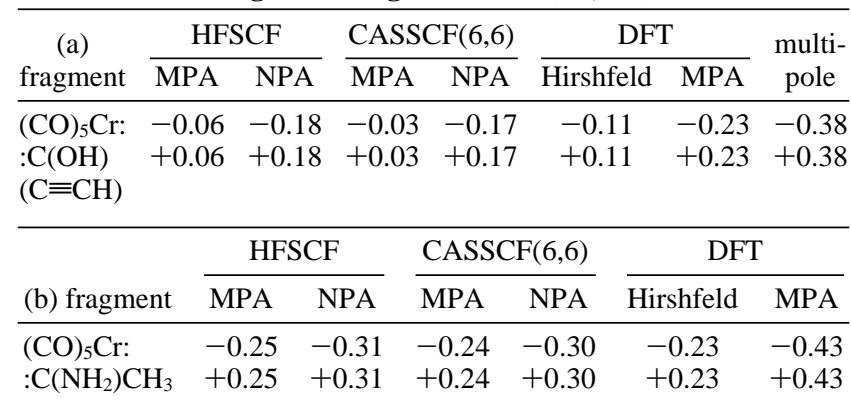

${ }^{a}$ MPA: Mulliken population analysis. NPA: Natural orbital population analysis.
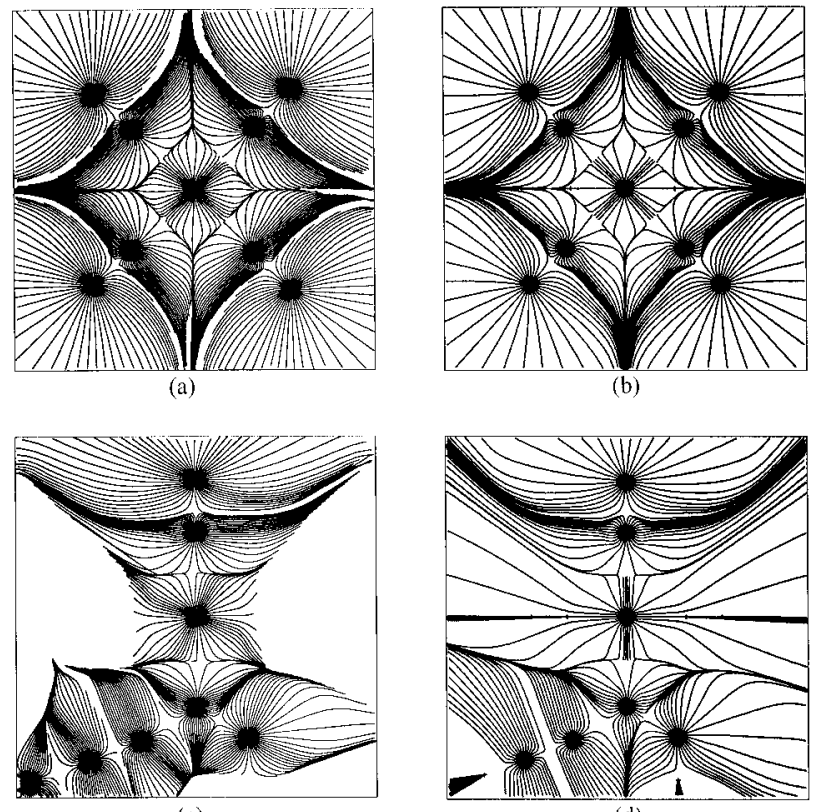

(c)

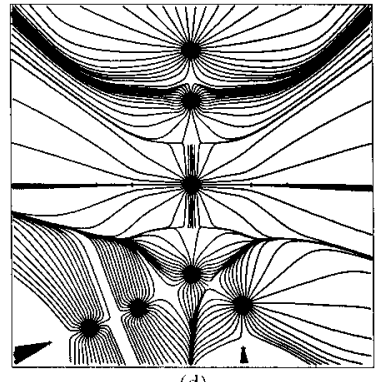

(d)

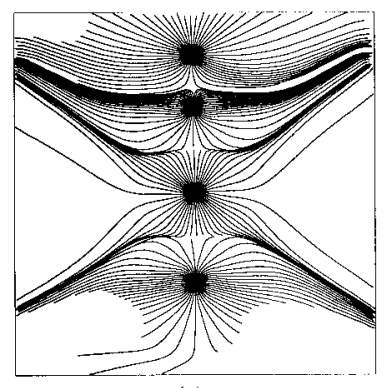

(e)

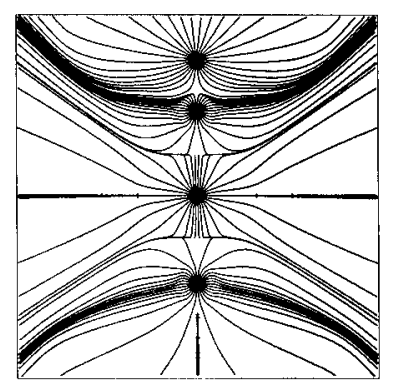

(c)
Figure 8. Gradient vector field, $\nabla \rho(r)$, of the electron density of $\mathbf{1}$ : $\mathrm{a}-\mathrm{f}$ are defined as in Figure 6.

The discrepancy found near $\mathrm{Cr}$ may be partially due to the thermal effect since the correlation between the multipole coefficients and the thermal parameters can not be neglected; data measured at even lower temperature (e.g. $10 \mathrm{~K}$ ) may resolve such problems in this respect. ${ }^{40 a, 86}$ Deformation density maps of three planes (as in Figures 2, 3, and 4) are calculated via HF and DFT methods on an amino carbene complex 2 . The maps are displayed in Figure 5. The essential features are identical to those in Figures 2, 3, and 4.

Laplacian of Electron Density. The Laplacian of the electron density, $\nabla^{2} \rho(r)$, can also display the density accumulation (where $\nabla^{2} \rho(r)<0$ ) and the density depletion $\left(\nabla^{2} \rho(r)>\right.$ $0)$. The advantage of the Laplacian over deformation is that it is unbiased from the promolecular model. ${ }^{20,87-89}$ The negative Laplacians, $-\nabla^{2} \rho(r)$, on three unique planes both from experiment and from HF calculation are shown in Figure 6. The 
TABLE 6: Topological Properties of Bond Critical Points of (a) 1 and (b) 2

(a) 1st line from experiment; 2nd line from theory; (b) from theory

\begin{tabular}{|c|c|c|c|c|c|c|c|c|c|}
\hline \multirow{2}{*}{$\begin{array}{c}\text { (a) } \\
\text { bond distance }^{a}(\AA)\end{array}$} & \multirow[b]{2}{*}{$\mathrm{d} 1^{b}(\AA)$} & \multirow[b]{2}{*}{$\mathrm{d} 2^{b}(\AA)$} & \multicolumn{3}{|c|}{ Hessian eigenvalues $\left(\mathrm{e} \AA^{-5}\right)$} & \multirow[b]{2}{*}{$\nabla^{2} \rho\left(r_{\mathrm{c}}\right)^{c}\left(\mathrm{e} \AA^{-5}\right)$} & \multirow[b]{2}{*}{$\rho\left(r_{\mathrm{c}}\right)\left(\mathrm{e} \AA^{-3}\right)$} & \multirow[b]{2}{*}{$\epsilon^{d}$} & \multirow[b]{2}{*}{$\left|\lambda_{1}\right| / \lambda_{3}$} \\
\hline & & & $\lambda_{1}$ & $\lambda_{2}$ & $\lambda_{3}$ & & & & \\
\hline $\mathrm{Cr}-\mathrm{C}_{\mathrm{cis}}{ }^{e}$ & 0.957 & 0.953 & -4.33 & -3.92 & 19.12 & 10.87 & 0.78 & 0.11 & 0.23 \\
\hline 1.910 & 0.921 & 0.989 & -1.46 & -1.43 & 19.18 & 16.29 & 0.61 & 0.02 & 0.07 \\
\hline $\mathrm{Cr}-\mathrm{C}_{\text {trans }}^{e}$ & 0.973 & 0.935 & -4.30 & -3.94 & 20.62 & 12.38 & 0.78 & 0.09 & 0.21 \\
\hline 1.906 & 0.923 & 0.987 & -1.82 & -1.01 & 19.15 & 16.32 & 0.61 & 0.81 & 0.10 \\
\hline $\mathrm{Cr}-\mathrm{C}_{\text {carb }}$ & 0.998 & 1.013 & -3.82 & -3.44 & 16.66 & 9.41 & 0.68 & 0.11 & 0.23 \\
\hline 2.011 & 0.942 & 1.069 & -1.44 & -1.15 & 15.55 & 12.96 & 0.56 & 0.26 & 0.09 \\
\hline$(\mathrm{C}-\mathrm{O})_{\mathrm{cis}^{e}}$ & 0.414 & 0.729 & -38.11 & -36.34 & 61.58 & -12.87 & 3.39 & 0.05 & 0.62 \\
\hline 1.143 & 0.388 & 0.755 & -34.55 & -34.52 & 78.90 & 9.83 & 2.67 & 0.00 & 0.44 \\
\hline$(\mathrm{C}-\mathrm{O})_{\text {trans }}$ & 0.404 & 0.744 & -37.13 & -34.34 & 76.80 & 5.33 & 3.22 & 0.08 & 0.48 \\
\hline 1.147 & 0.390 & 0.757 & -34.08 & -33.96 & 76.88 & 8.83 & 2.65 & 0.00 & 0.44 \\
\hline $\mathrm{C}_{\text {carb }}-\mathrm{O}$ & 0.537 & 0.785 & -17.71 & -16.19 & 20.80 & -13.10 & 2.14 & 0.09 & 0.85 \\
\hline 1.321 & 0.441 & 0.880 & -17.16 & -10.81 & 25.86 & -2.11 & 1.68 & 0.59 & 0.66 \\
\hline $\mathrm{C}_{\mathrm{carb}}-\mathrm{C} 8$ & 0.694 & 0.723 & -14.86 & -12.79 & 12.60 & -15.05 & 1.91 & 0.16 & 1.18 \\
\hline 1.416 & 0.667 & 0.749 & -13.08 & -12.48 & 8.58 & -16.98 & 1.68 & 0.05 & 1.52 \\
\hline $\mathrm{C} 8-\mathrm{C} 9$ & 0.515 & 0.706 & -19.53 & -16.92 & 15.23 & -21.22 & 2.73 & 0.15 & 1.28 \\
\hline 1.220 & 0.593 & 0.629 & -15.13 & -14.60 & 2.51 & -27.23 & 2.29 & 0.04 & 6.03 \\
\hline \multicolumn{10}{|l|}{ (b) } \\
\hline $\begin{array}{l}\mathrm{Cr}-\mathrm{C}_{\mathrm{cis}} \\
1.884\end{array}$ & 0.914 & 0.970 & -1.75 & -1.55 & 20.31 & 17.01 & 0.65 & 0.13 & 0.09 \\
\hline $\begin{array}{l}\mathrm{Cr}-\mathrm{C}_{\text {trans }} \\
1.857\end{array}$ & 0.907 & 0.950 & -1.90 & -1.50 & 21.40 & 18.00 & 0.70 & 0.26 & 0.09 \\
\hline $\begin{array}{l}\mathrm{Cr}-\mathrm{C}_{\text {carb }} \\
2.081\end{array}$ & 0.965 & 1.117 & -1.06 & 1.00 & 13.05 & 10.99 & 0.49 & 0.07 & 0.08 \\
\hline $\begin{array}{l}(\mathrm{C}-\mathrm{O})_{\mathrm{cis}} \\
1.135\end{array}$ & 0.387 & 0.751 & -35.36 & -35.31 & 82.27 & 11.60 & 2.71 & 0.00 & 0.43 \\
\hline $\begin{array}{l}(\mathrm{C}-\mathrm{O})_{\text {trans }} \\
1.152\end{array}$ & 0.390 & 0.757 & -34.07 & -34.01 & 76.29 & 8.21 & 2.66 & 0.00 & 0.45 \\
\hline $\begin{array}{l}\mathrm{C}_{\text {carb }}-\mathrm{N} \\
1.293\end{array}$ & 0.437 & 0.857 & -20.38 & -14.16 & 23.59 & -10.96 & 1.99 & 0.44 & 0.86 \\
\hline $\begin{array}{l}\mathrm{C}_{\text {carb }}-\mathrm{C} 7 \\
1.486\end{array}$ & 0.761 & 0.726 & -11.14 & -10.66 & 9.12 & -12.68 & 1.51 & 0.04 & 1.22 \\
\hline
\end{tabular}

${ }^{a}$ Obtained from multipole refinement. ${ }^{b} d 1, d 2$ : distances from BCP to the first and second atom of the bond. ${ }^{c}$ Laplacian at critical point (BCP) $\nabla^{2} \rho\left(r_{\mathrm{c}}\right)=\left(\lambda_{1}+\lambda_{2}+\lambda_{3}\right) .{ }^{d}$ Ellipticity, $\epsilon=\left|\lambda_{1} / \lambda_{2}\right|-1 .{ }^{e}$ Average value of four cis ones.

agreement between experiment and theory is very good, and the feature in the bond density accumulation is quite in correspondence with that in the deformation density. To clarify the asphericity in electron density near the $\mathrm{Cr}$ nucleus, the enlarged Laplacian maps at the $\mathrm{Cr}$ center are displayed in Figure 7. The accumulation in the $\mathrm{d}_{\pi}$ directions and the depletion along the $\mathrm{d}_{\sigma}(\mathrm{Cr}-\mathrm{C})$ directions are clearly depicted. Unlike the descrepancies found in experimental and theoretical deformation density around $\mathrm{Cr}$, the features in the density concentration and density depletion are similar between experiment and theory, but the valence shell charge concentration (VSCC) ${ }^{33}$ in experimental maps (Figure $7 \mathrm{c}, \mathrm{e})$ tilts by a small angle $\left(\sim 10^{\circ}\right)$ with respect to that in theoretical ones (Figure 7d,f). The inner shells of the $\mathrm{Cr}$ core are also displayed neatly in this figure. It seems advantageous using the Laplacian over deformation density to investigate the aspheric density distribution around the $3 \mathrm{~d}$ transition metal, where the density accumulation and the density depletion are derived solely on the total electron density; no promolecular density is required. The corresponding theoretical Laplacian maps on amino carbene 2 give almost the same feature as in Figure 6 and 7; they are provided in the Supporting Information.

d Orbital Population and Net Atomic Charge. The d orbital populations of the $\mathrm{Cr}$ atom in compounds $\mathbf{1}$ and $\mathbf{2}$ are listed in Table 4, where the experiment is available only for compound 1 . The calculated ones include ab initio calculations at both HFSCF and CASSCF $(6,6)$ levels and the DFT method. The agreement between various calculations in different partitions is reasonable, with less population on $\mathrm{d}_{\sigma}$ orbitals $\left(\mathrm{d}_{x y}\right.$ and $\left.\mathrm{d}_{z}{ }^{2}\right)$ than on $\mathrm{d}_{\pi}$ orbitals $\left(\mathrm{d}_{x^{2}-y^{2}}, \mathrm{~d}_{y z}\right.$, and $\left.\mathrm{d}_{x z}\right)$. No difference in $\mathrm{d}$ orbital populations is detectable between alkoxy- and amino- chromium carbenes, just as they are in Laplacian maps. The difference in atomic charges between the HFSCF and CASSCF calculations is minimal, but the difference in charges from various ways of partition is large. These differences are discussed extensively elsewhere. ${ }^{90}$ Nevertheless, it is interesting to notice that charges of two fragments shown in Table 5 are such that the $(\mathrm{CO})_{5} \mathrm{Cr}$ fragment is an electron acceptor $(-0.38)$ and the carbene fragment, $: \mathrm{C}\left(\mathrm{XR}_{1}\right)\left(\mathrm{R}_{2}\right)$, is an electron donor $(+0.38)$ in experiment, which is in accord with all the calculations in compound $\mathbf{1}$. The electron donor/acceptor roles for the two fragments are therefore clear.

Gradient Vector Field and Bond Critical Points. The gradient vector field on the total electron density of $\mathbf{1}, \nabla \rho(r)$, is depicted in Figure 8 with three projections around the $\mathrm{Cr}$ atom. The agreement between experiment and theory is reasonably good. The bond critical point (BCP) and the atomic basin (domain) are easily recognized from the figure. To clarify such BCP and atom domain, the BCP of each chemical bond and atom domain are displayed in Figure 9 together with the bond path and the total electron density. Again the agreement between experiment and theory is good. The detailed properties at the BCP are given in Table 6 , where $\lambda_{1}, \lambda_{2}$, and $\lambda_{3}$ are the eigenvalues of the Hessian matrix at the BCP, representing the Laplacian values perpendicular $\left(\lambda_{1}, \lambda_{2}\right)$ and along $\left(\lambda_{3}\right)$ the bond direction. ${ }^{33}$ Apparently all $\mathrm{Cr}-\mathrm{C}$ bonds can be characterized as a closed shell interaction according to the positive Laplacian value at the BCP and with $\rho\left(r_{\mathrm{c}}\right)$ and $\left|\lambda_{1}\right| / \lambda_{3}$ values much less than 1 . This is consistent with the results from the NBO analysis in either the HF or CASSCF calculation, where the $\mathrm{Cr}-\mathrm{C}$ bond is analyzed as partially dative and partially covalent. The carbonyl $\mathrm{C} \equiv \mathrm{O}$ and $\mathrm{C} \equiv \mathrm{C}$ triple bonds obviously belong to shared 


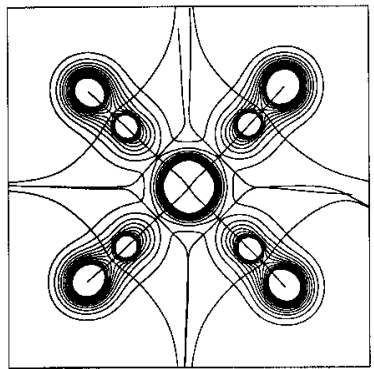

(a)

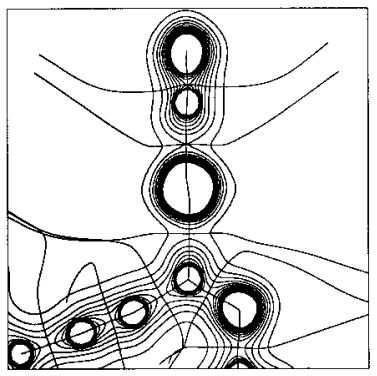

(c)

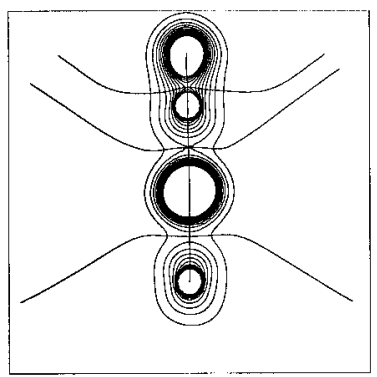

(e)

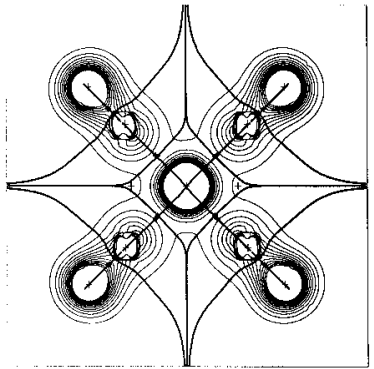

(b)

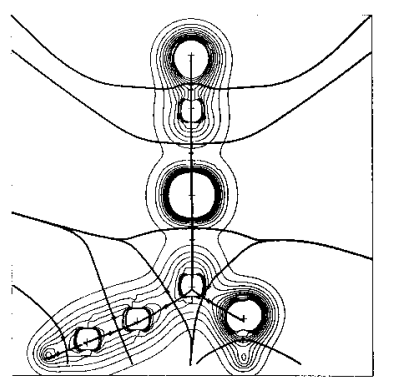

(d)

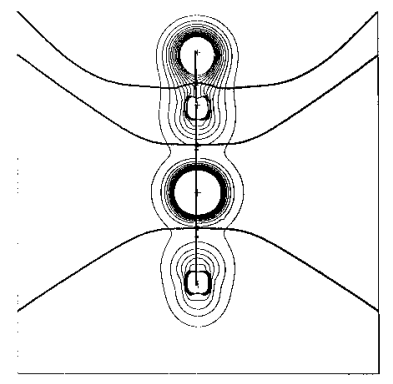

(f)
Figure 9. Total density, bond path, and atom domain of 1: a-f are defined as in Figure 6. Contour interval of total density $0.4 \mathrm{e}^{-3}$.

interactions with high $\rho\left(r_{\mathrm{c}}\right)$ and low ellipticity $(\epsilon)$. The positive Laplacian value of $\mathrm{C} \equiv \mathrm{O}$ from theory was also found earlier on carbon monoxide by Bader et al. ${ }^{33}$ due to the density polarization or transfer of charge from $\mathrm{C}$ to $\mathrm{O}$ in such a short bond. This is a general observation for all short $\mathrm{C}-\mathrm{O}$ bonds with the result that the BCP lies just within the inner shell of charge depletion, thus making $\lambda_{3}$ a very large positive value. However, the large negative values of $\lambda_{1}$ and $\lambda_{2}$ are still indicative of a strong shared interaction for all the carbonyl $\mathrm{C}-\mathrm{O}$ bonds. If only $\lambda_{1}, \lambda_{2}$ values are taken into account, the values of $(\mathrm{C}-\mathrm{O})_{\text {trans }}$ and $(\mathrm{C}-\mathrm{O})_{\text {cis }}$ in $\mathbf{1}$ are the same, but the values of $(\mathrm{C}-\mathrm{O})_{\text {cis }}$ are slightly more negative than those of $(\mathrm{C}-\mathrm{O})_{\text {trans }}$ in 2 , indicating that $(\mathrm{C}-\mathrm{O})_{\text {cis }}$ is a slightly stronger bond than $(\mathrm{C}-\mathrm{O})_{\text {trans. }}$ This is in agreement with the NBO analysis of CASSCF result. In this respect, the experimental one seems better represented because the $\mathrm{BCP}$ from experiment is located not so close to $\mathrm{C}(\mathrm{d} 1)$ as that of the theoretical one. The values of $\rho\left(r_{\mathrm{c}}\right)$ are in agreement with the bond order obtained from NBO analyses. However, the $\rho\left(r_{\mathrm{c}}\right)$ values of $(\mathrm{C}-\mathrm{O})_{\text {cis }}$ and $(\mathrm{C}-\mathrm{O})_{\text {trans }}$ in $\mathbf{2}$ are not so much different as indicated in the NBO analysis.

Frontier Orbitals. Molecular orbital calculation based on the HFSCF method indicates that the LUMO of the title complex mainly consists of a $\pi^{*} \mathrm{Cr}-\mathrm{C} 6$ and a $\pi^{*} \mathrm{C} 8-\mathrm{C} 9$, with high coefficients on the carbene carbon (C6) and acetylene carbon atoms $(\mathrm{C} 8, \mathrm{C} 9)$. The 1,3-dipolar cycloaddition is known to take place at the triple bond $(\mathrm{C} 8 \equiv \mathrm{C} 9) .{ }^{91,92}$ The catalytic effects of the Fischer carbene toward the diene cycloaddition reaction can be interpreted as the HOMO/LUMO energy gap of the Fischer carbene being far less than those of corresponding ketones.

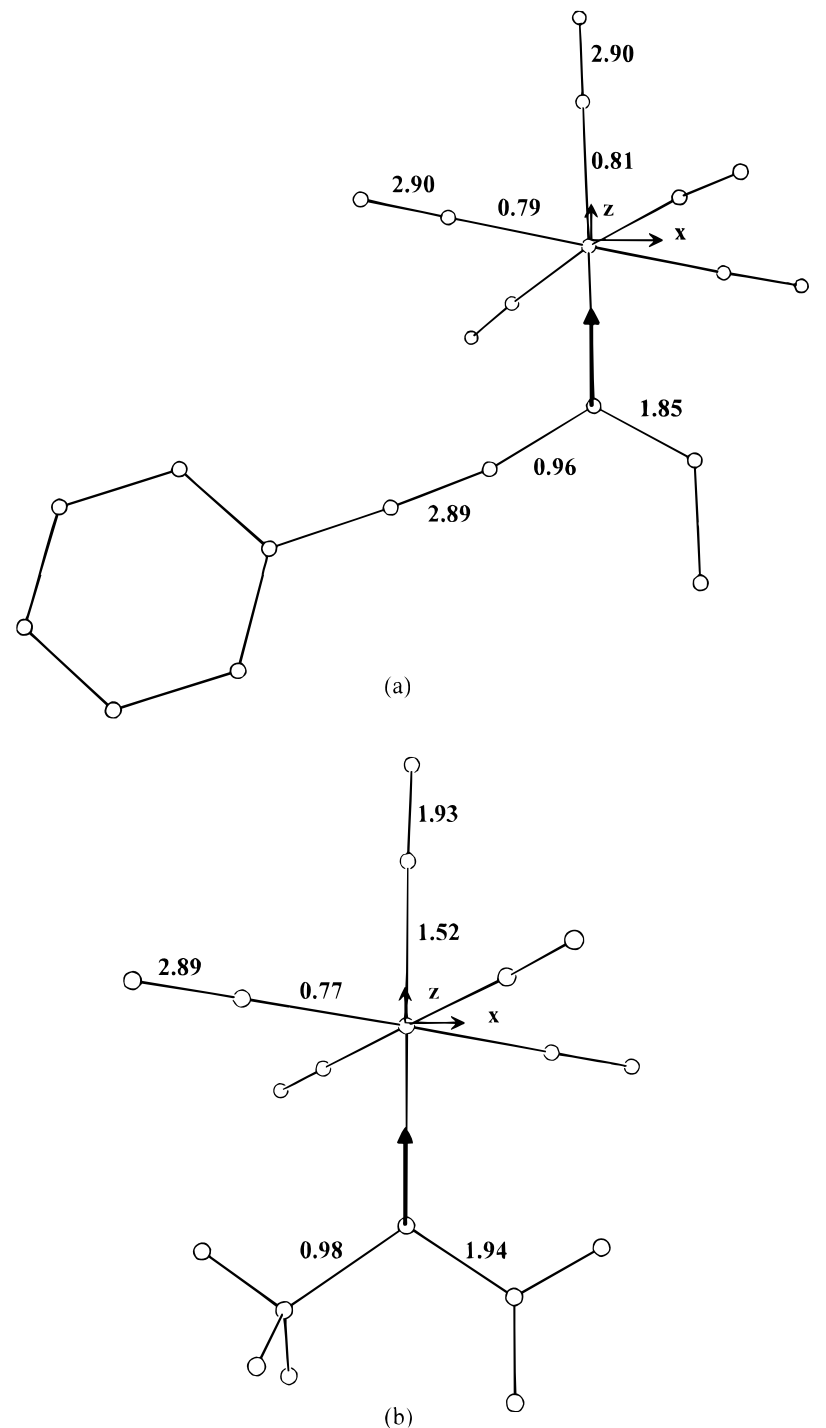

Figure 10. Local coordinate (Cr) and bond orders of (a) 1 and (b) 2 derived from $\operatorname{CASSCF}(6,6)$ calculations.

CASSCF. The result of $\operatorname{CASSCF}(6,6)$ shows that the HF ground state is obviously the dominant configuration, with a coefficient of 0.95 for both 1 and 2 . Similar results are found in CI calculations of molybdenum carbene, with the coefficient of the $\mathrm{HF}$ ground state being 0.98 and 0.97 for $(\mathrm{CO})_{5} \mathrm{Mo}=\mathrm{CH}-$ $(\mathrm{OH})$ and $(\mathrm{CO})_{5} \mathrm{Mo}=\mathrm{CH}_{2}$, respectively. ${ }^{19}$ The following CASS$\mathrm{CF}(8,8)$ calculation $^{21}$ on the latter compound gives 0.94 . The double excitations $\left(\pi_{1}^{2} \rightarrow \pi_{1}^{*}{ }^{2} \sigma^{2} \rightarrow \sigma^{* 2}, \pi_{2}^{* 2} \rightarrow \pi_{2}^{*}{ }^{2} \sigma \pi_{1} \rightarrow\right.$ $\sigma^{*} \pi_{1}^{*}$, and $\sigma \pi_{2} \rightarrow \sigma^{*} \pi_{2}^{*}$ ) are the important configurations, with coefficients in the range $0.10-0.17$ for both compounds. Detailed analyses of the chemical bonds via wave functions obtained from HFSCF and $\operatorname{CASSCF}(6,6)$ calculations are performed using NBO analysis. The bond orders of the two molecules 1 and $\mathbf{2}$ from $\operatorname{CASSCF}(6,6)$ are listed in Figure 10. It is interesting to note that the main difference in the bond orders given in the figure is that the trans $\mathrm{Cr}-\mathrm{C}_{\text {carbonyl }}$ and carbonyl $\mathrm{C}-\mathrm{O}$ bonds of $\mathbf{2}$ are of double-bond character, whereas in 1 the trans $\mathrm{Cr}-\mathrm{C}_{\text {carbonyl }}$ is still a single bond. This CAS result is consistent with the corresponding bond distances (Table 3 ). For $\mathrm{Cr}-\mathrm{C}_{\text {carbene }}$ and $\mathrm{C}-\mathrm{X}$ bonds, they are a single and double bond, respectively, in both compounds. cis $\mathrm{Cr}-\mathrm{C}_{\text {carbonyl }}$ are all single and cis carbonyl $\mathrm{C}-\mathrm{O}$ are all triple bonds. $\mathrm{C} 8-\mathrm{C} 9$ in 1 is a triple bond. Further detailed analyses of $\mathrm{Cr}-\mathrm{C}_{\text {carbene }}, \mathrm{Cr}-$ $\mathrm{CO}_{\text {trans }}, \mathrm{C}_{\text {carbene }}-\mathrm{O}$ and $(\mathrm{C}-\mathrm{O})_{\text {trans }}$ bonds of $\mathbf{1}$ into $\sigma$ and $\pi$ 
TABLE 7: Natural Hybrid Orbital Analysis and Bond Occupancies of (a) 1; (b) 2

(a)

\begin{tabular}{|c|c|c|c|c|c|c|c|c|c|c|c|}
\hline & \multicolumn{2}{|c|}{$\begin{array}{c}\mathrm{Cr}-\mathrm{C}_{\text {carbene }} \\
\mathrm{HFSCF}\end{array}$} & & \multicolumn{2}{|c|}{$\begin{array}{c}\mathrm{C}_{\text {carbene }}-\mathrm{O} \\
\text { HFSCF }\end{array}$} & & \multicolumn{2}{|c|}{$\begin{array}{c}\mathrm{Cr}-\mathrm{C}_{\text {trans }} \\
\mathrm{HFSCF}\end{array}$} & & \multicolumn{2}{|c|}{$\begin{array}{c}(\mathrm{C}-\mathrm{O})_{\text {trans }} \\
\text { HFSCF }\end{array}$} \\
\hline & $\mathrm{NHO}(\%)$ & occ. & & $\mathrm{NHO}(\%)$ & occ. & & $\mathrm{NHO}(\%)$ & occ. & & $\mathrm{NHO}(\%)$ & occ. \\
\hline$\sigma$ & $\mathrm{C} \mathrm{sp} z(100)$ & 1.557 & $\sigma$ & $\begin{array}{l}\text { C } \mathrm{sp}_{x} \mathrm{p}_{z}(30) \\
\mathrm{O} \mathrm{sp}_{x} \mathrm{p}_{z}(70)\end{array}$ & 1.991 & $\sigma$ & $\begin{array}{l}\mathrm{Cr} \mathrm{sd}_{z^{2}}(23) \\
\mathrm{C} \mathrm{sp} \mathrm{sp}_{z}(77)\end{array}$ & 1.952 & $\sigma$ & $\begin{array}{l}\mathrm{Csp}(30) \\
\mathrm{O} \mathrm{sp} z(70)\end{array}$ & 1.997 \\
\hline $\mathrm{n}$ & $\operatorname{Crd}_{y z}(100)$ & 1.578 & $\pi$ & $\begin{array}{l}\mathrm{C} \mathrm{p}_{y}(11) \\
\mathrm{O} \mathrm{p}_{y}(89)\end{array}$ & 1.994 & & & & $\pi_{x}$ & $\begin{array}{l}\mathrm{C} \mathrm{p}_{x}(22) \\
\mathrm{O} \mathrm{p}_{x}(78)\end{array}$ & 1.999 \\
\hline $\mathrm{n}$ & $\mathrm{Cr} \mathrm{d}_{x z}(100)$ & 1.756 & & & & & & & $\pi_{y}$ & $\begin{array}{l}\mathrm{C} \mathrm{p}_{y}(22) \\
\mathrm{O} \mathrm{p}_{y}(78)\end{array}$ & 1.996 \\
\hline
\end{tabular}

\begin{tabular}{|c|c|c|c|c|c|c|c|c|c|c|c|}
\hline & \multicolumn{2}{|c|}{ CASSCF } & & \multicolumn{2}{|c|}{ CASSCF } & & \multicolumn{2}{|c|}{ CASSCF } & & \multicolumn{2}{|c|}{ CASSCF } \\
\hline & $\mathrm{NHO}(\%)$ & Occ. & & $\mathrm{NHO}(\%)$ & Occ. & & $\mathrm{NHO}(\%)$ & Occ. & & $\mathrm{NHO}(\%)$ & Occ. \\
\hline$\sigma$ & $\mathrm{C} \mathrm{sp} z(100)$ & 1.554 & $\sigma$ & $\begin{array}{l}\mathrm{C} \mathrm{sp}_{x} \mathrm{p}_{z}(30) \\
\mathrm{O} \mathrm{sp}_{x} \mathrm{p}_{z}(70)\end{array}$ & 1.992 & $\sigma$ & $\begin{array}{l}\mathrm{Cr} \mathrm{sd}_{z^{2}(23)} \\
\mathrm{C} \mathrm{sp} \mathrm{sp}_{z}(77)\end{array}$ & 1.953 & $\sigma$ & $\begin{array}{l}\mathrm{C} \mathrm{sp}_{z}(30) \\
\mathrm{O} \mathrm{sp}_{z}(70)\end{array}$ & 1.997 \\
\hline $\mathrm{n}$ & $\operatorname{Crd}_{y z}(100)$ & 1.584 & $\pi$ & $\begin{array}{l}\mathrm{C} \mathrm{p}_{y}(13) \\
\mathrm{O} \mathrm{p}_{y}(87)\end{array}$ & 1.992 & & & & $\pi_{x}$ & $\begin{array}{l}\mathrm{C} \mathrm{p}_{x}(22) \\
\mathrm{O} \mathrm{p}_{x}(78)\end{array}$ & 1.999 \\
\hline $\mathrm{n}$ & $\mathrm{Crd}_{x z}(100)$ & 1.749 & & & & & & & $\pi_{y}$ & $\begin{array}{l}\mathrm{C} \mathrm{p}_{y}(23) \\
\mathrm{O} \mathrm{p}_{y}(77)\end{array}$ & 1.997 \\
\hline
\end{tabular}

(b)

\begin{tabular}{|c|c|c|c|c|c|c|c|c|c|c|c|}
\hline & \multicolumn{2}{|c|}{$\begin{array}{c}\mathrm{Cr}-\mathrm{C}_{\text {carbene }} \\
\mathrm{HFSCF}\end{array}$} & & \multicolumn{2}{|c|}{$\begin{array}{c}\mathrm{C}_{\text {carbene }}-\mathrm{N} \\
\text { HFSCF }\end{array}$} & & \multicolumn{2}{|c|}{$\begin{array}{c}\mathrm{Cr}-\mathrm{C}_{\text {trans }} \\
\text { HFSCF }\end{array}$} & & \multicolumn{2}{|c|}{$\begin{array}{c}(\mathrm{C}-\mathrm{O})_{\text {trans }} \\
\text { HFSCF }\end{array}$} \\
\hline & $\mathrm{NHO}(\%)$ & occ. & & $\mathrm{NHO}(\%)$ & occ. & & $\mathrm{NHO}(\%)$ & occ. & & $\mathrm{NHO}(\%)$ & occ. \\
\hline$\sigma$ & $\mathrm{C} \mathrm{sp} z(100)$ & 1.584 & $\sigma$ & $\begin{array}{l}\text { C } \operatorname{sp}_{x} \mathrm{p}_{z}(36) \\
\mathrm{N} \mathrm{sp}_{x} \mathrm{p}_{\mathrm{p}}(64)\end{array}$ & 1.990 & $\sigma$ & 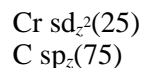 & 1.949 & $\sigma$ & $\begin{array}{l}\mathrm{C} \operatorname{sp}_{z}(30) \\
\mathrm{O} \mathrm{sp}_{z}(70)\end{array}$ & 1.998 \\
\hline $\mathrm{n}$ & $\operatorname{Crd}_{y z}(100)$ & 1.694 & $\pi$ & $\begin{array}{l}\mathrm{Cp}_{y}(17) \\
\mathrm{N} \mathrm{p}_{y}(83)\end{array}$ & 1.996 & & & & $\pi_{x}$ & $\begin{array}{l}\mathrm{C} \mathrm{p}_{x}(22) \\
\mathrm{O} \mathrm{p}_{x}(78)\end{array}$ & 1.999 \\
\hline \multirow[t]{3}{*}{$\mathrm{n}$} & $\operatorname{Crd}_{x z}(100)$ & 1.767 & & & & & & & $\pi_{y}$ & $\begin{array}{l}\mathrm{C} \mathrm{p}_{y}(22) \\
\mathrm{O} \mathrm{p}_{y}(78)\end{array}$ & 1.997 \\
\hline & \multicolumn{2}{|c|}{ CASSCF } & & \multicolumn{2}{|c|}{ CASSCF } & & \multicolumn{2}{|c|}{ CASSCF } & & \multicolumn{2}{|c|}{ CASSCF } \\
\hline & $\mathrm{NHO}(\%)$ & Occ. & & $\mathrm{NHO}(\%)$ & Occ. & & $\mathrm{NHO}(\%)$ & Occ. & & $\mathrm{NHO}(\%)$ & Occ. \\
\hline$\sigma$ & $\mathrm{Csp}_{z}(100)$ & 1.585 & $\sigma$ & $\begin{array}{l}\mathrm{C} \mathrm{sp}_{x} \mathrm{p}_{z}(36) \\
\mathrm{N} \mathrm{sp}_{x} \mathrm{p}_{z}(64)\end{array}$ & 1.990 & $\sigma$ & $\begin{array}{l}\mathrm{Cr} \mathrm{sd}_{z^{2}}(23) \\
\mathrm{C} \mathrm{sp} z(77)\end{array}$ & 1.949 & $\sigma$ & $\begin{array}{l}\mathrm{C} \mathrm{sp}_{z}(30) \\
\mathrm{O} \mathrm{sp}_{z}(70)\end{array}$ & 1.997 \\
\hline $\mathrm{n}$ & $\operatorname{Crd}_{y z}(100)$ & 1.592 & $\pi$ & $\begin{array}{l}\mathrm{C} \mathrm{p}_{y}(20) \\
\mathrm{N} \mathrm{p}_{y}(80)\end{array}$ & 1.995 & $\pi$ & $\begin{array}{l}\mathrm{Cr} \mathrm{d}_{x z}(93) \\
\mathrm{C}_{x}(7)\end{array}$ & 1.833 & $\pi_{y}$ & $\begin{array}{l}\mathrm{C} \mathrm{p}_{y}(22) \\
\mathrm{O} \mathrm{p}_{y}(78) \\
\mathrm{O} \mathrm{p}_{x}(100)\end{array}$ & $\begin{array}{l}1.998 \\
1.586\end{array}$ \\
\hline
\end{tabular}

characteristics from both HFSCF and CASSCF calculations are listed on Table $7 \mathrm{a}$. The $\mathrm{p}_{\pi}$ orbital of the carbene carbon forms $\mathrm{a} \pi$ bond with the $\mathrm{p}_{\pi}$ orbital of the $\mathrm{O}$ atom in both results. The $\pi$ bond density is not evenly distributed between the two centers but polarized toward $\mathrm{O}(87 \%$ from $\mathrm{O})$; that is, there is little $\pi$ density on the carbene carbon in either case. This leads to a feasible understanding of the nucleophilic attack at the carbene carbon site. The same analyses on compound $\mathbf{2}$ are given in Table $7 \mathrm{~b}$, where the $\mathrm{Cr}-\mathrm{C}_{\text {carbene }}$ bond is single in both HFSCF and CASSCF calculations; however the $\mathrm{Cr}-\mathrm{CO}_{\text {trans }}$ bond is double in CASSCF. The $\pi$ bond is formed between $\mathrm{d}_{x z}$ of $\mathrm{Cr}$ and $\mathrm{p}_{x}$ of $\mathrm{C}_{\text {trans }}$ but with dominant contribution (93\%) from $\mathrm{Cr}$. The $\mathrm{C}_{\text {carbene }}-\mathrm{N}$ double bond is again mainly contributed from the $\mathrm{N} \mathrm{p}_{y}$ orbitals $(80 \%)$. So in compound $\mathbf{2}$, the density along the $\mathrm{p}_{y}$ direction of the carbene carbon is also small $(20 \%)$.

Orbital Correlation Diagram. A useful way of understanding the nature of the $\mathrm{Cr}-\mathrm{C}_{\text {carbene }}$ bond is to correlate the MOs of the metal carbonyl fragment with the MOs of the carbene fragments, where one fragment, $: \mathrm{Cr}(\mathrm{CO})_{5}$, is in $C_{4 v}$ symmetry and the other fragment, $: \mathrm{C}(\mathrm{OH})(\mathrm{C} \equiv \mathrm{CH})$ or : $\mathrm{C}\left(\mathrm{NH}_{2}\right) \mathrm{CH}_{3}$, is in $C_{s}$ symmetry. Orbital correlation diagrams of $\mathbf{1}$ and $\mathbf{2}$ are given in Figure 11a,b. Five d orbitals of $\mathrm{Cr}$ are split into $\mathrm{b}_{2}, \mathrm{e}, \mathrm{a}_{1}$, and $\mathrm{b}_{1}$ states in $C_{4 v}$. The $\mathrm{a}_{1}\left(\mathrm{~d}_{z^{2}}\right)$ orbital, which is pointed toward the carbene carbon, forms a $\sigma$ bond with the $\mathrm{sp}^{2}$ hybrid orbital of the carbene carbon, and one of the e orbitals ( $\mathrm{a}^{\prime \prime}$ in $C_{s}$ ) forms a $\pi$ bond with the $\mathrm{p}_{\pi}$ orbital of the carbene carbon. According to these correlation diagrams, it is clear that the carbene fragment mainly serves as a $\sigma$ donor but only slightly as a $\pi$ acceptor. The $\mathrm{Cr}-\mathrm{C} \pi$ bond orbital $\left(\mathrm{a}^{\prime \prime}\right)$ can be described as the combination between the $\mathrm{d}_{y z}$ orbital of $\mathrm{Cr}$ and the $\pi_{\mathrm{C}-\mathrm{X}}$ and $\pi{ }^{*}-\mathrm{X}$ of carbene, shown in Figure 11. Therefore this $\pi$ bond is best described as a three-centered four-electron $\pi$ bond. Thus, it is reasonable to say that the $\pi$ bond density is very polarized toward $\mathrm{Cr}$ or $\mathrm{X}$ atoms. The $\sigma$ donor character is consistent with the fragment charge given above, where the carbene fragment is positive and the $(\mathrm{CO})_{5} \mathrm{Cr}$ fragment is negative. One important fact is that the energy of the $\pi^{*} \mathrm{C}-\mathrm{N}$ orbital of the carbene fragment in $\mathbf{2}$ is very close to that of $\pi^{*} \mathrm{CO}$ (trans). Contrarily, the energy of the $\pi^{*} \mathrm{C}-\mathrm{O}$,carbene orbital of compound $\mathbf{1}$ is far lower than that of $\pi^{*}$ carbonyl. This gives a plausible explanation for the $\pi$ bond being formed at $\mathrm{Cr}-\mathrm{CO}_{\text {trans }}$ in $\mathbf{2}$ but not in $\mathbf{1}$.

Fermi Hole Density. The Fermi hole function is useful in describing the electron delocalization ${ }^{93}$ and in leading to the understanding of electron pairs. ${ }^{94}$ Such Fermi hole functions are applied to the bonding characterization of $(\mathrm{OC})_{\text {trans }}-\mathrm{Cr}-$ $\mathrm{C}-\mathrm{X}$. The reference electron $(\mathbf{O})$ is placed on four atoms successively, but 0.5 au above the nuclear position in the $\pi$ bond direction; the results of $\mathbf{1}$ and $\mathbf{2}$ are displayed in Figure 12. The delocalized $\pi$ character through the trans carbonyl group is clearly indicated when the reference electron is at $\mathrm{Cr}$. The three-centered $\pi$ bond is apparent when the reference electron is placed on either $\mathrm{C}_{\text {carbene }}$ or $\mathrm{X}$. But the difference between the bonding of $\mathrm{Cr}-\mathrm{CO}_{\text {trans }}$ on $\mathbf{1}$ and $\mathbf{2}$ based on the 
TABLE 8: Observed and Calculated Ionization Potentials for $(\mathrm{CO})_{5} \mathrm{Cr}\left(\mathrm{XR}^{\prime}\right) \mathrm{R}$

\begin{tabular}{|c|c|c|c|c|}
\hline orbital & observed $^{5}$ & DFT & $\mathrm{HF}$ & Fenske-Hall ${ }^{5}$ \\
\hline \multicolumn{5}{|c|}{$\mathrm{XR}^{\prime}=\mathrm{NH}_{2} ; \mathrm{R}=\mathrm{C}_{6} \mathrm{H}_{5}$} \\
\hline $\mathrm{Cr} 3 \mathrm{~d}_{y z}$ & 7.25 & 7.77 & 8.29 & 8.12 \\
\hline $\operatorname{Cr} 3 \mathrm{~d}_{x z}$ & 7.52 & 7.98 & 8.34 & 8.60 \\
\hline $\operatorname{Cr} 3 \mathrm{~d}_{x^{2}-y^{2}}$ & 7.73 & 8.16 & 8.67 & 8.89 \\
\hline $\mathrm{Ph}$ & 9.23 & 9.18 & 9.79 & 14.59 \\
\hline $\mathrm{Ph}$ & 9.52 & 9.34 & 9.97 & 14.84 \\
\hline$\sigma^{*}$ & 9.80 & 10.18 & 11.99 & 12.15 \\
\hline $\mathrm{C}-\mathrm{N}$ & & 11.06 & 13.81 & 18.83 \\
\hline $\mathrm{Ph}$ & 10.52 & 11.44 & 14.26 & 17.92 \\
\hline $\mathrm{Ph}$ & & 11.60 & 14.53 & 18.65 \\
\hline \multicolumn{5}{|c|}{$\mathrm{XR}^{\prime}=\mathrm{NMe}_{2} ; \mathrm{R}=\mathrm{C}_{6} \mathrm{H}_{5}$} \\
\hline $\mathrm{Cr} 3 \mathrm{~d}_{y z}$ & 7.02 & 7.49 & 8.05 & 7.94 \\
\hline $\operatorname{Cr} 3 \mathrm{~d}_{x z}$ & 7.26 & 7.72 & 8.19 & 8.33 \\
\hline $\operatorname{Cr} 3 \mathrm{~d}_{x^{2}-y^{2}}$ & 7.54 & 7.92 & 8.56 & 8.75 \\
\hline $\mathrm{Ph}$ & 8.87 & 8.80 & 9.48 & 14.43 \\
\hline $\mathrm{Ph}$ & 8.87 & 9.10 & 9.74 & 14.45 \\
\hline$\sigma^{*}$ & 9.49 & 9.94 & 11.73 & 11.74 \\
\hline $\mathrm{C}-\mathrm{N}$ & 10.58 & 10.36 & 12.37 & 15.98 \\
\hline $\mathrm{Ph}$ & 10.16 & 11.23 & 14.31 & 17.71 \\
\hline $\mathrm{Ph}$ & 10.96 & 11.37 & 14.35 & 18.16 \\
\hline \multicolumn{5}{|c|}{$\mathrm{XR}^{\prime}=\mathrm{OMe} ; \mathrm{R}=\mathrm{C}_{6} \mathrm{H}_{5}$} \\
\hline $\mathrm{Cr} 3 \mathrm{~d}_{y z}$ & 7.39 & 7.83 & 8.30 & 8.27 \\
\hline $\operatorname{Cr} 3 \mathrm{~d}_{x z}$ & 7.78 & 8.23 & 8.73 & 9.11 \\
\hline $\operatorname{Cr} 3 \mathrm{~d}_{x^{2}-y^{2}}$ & 7.78 & 8.85 & 9.05 & 9.15 \\
\hline$\sigma^{*}$ & 9.26 & 8.98 & 9.41 & 11.28 \\
\hline $\mathrm{Ph}$ & 9.66 & 9.01 & 9.78 & 14.36 \\
\hline $\mathrm{Ph}$ & 10.06 & 9.81 & 11.78 & 14.53 \\
\hline $\mathrm{Ph}$ & & 10.73 & 13.37 & 17.90 \\
\hline $\mathrm{Ph}$ & & 11.40 & 14.09 & 18.22 \\
\hline \multicolumn{5}{|c|}{$\mathrm{XR}^{\prime}=\mathrm{NH}_{2} ; \mathrm{R}=\mathrm{CH}_{3}$} \\
\hline $\operatorname{Cr} 3 \mathrm{~d}_{y z}$ & 7.45 & 8.05 & 8.15 & 8.03 \\
\hline $\operatorname{Cr} 3 \mathrm{~d}_{x z}$ & 7.80 & 8.26 & 8.35 & 8.51 \\
\hline $\operatorname{Cr} 3 \mathrm{~d}_{x^{2}-y^{2}}$ & 7.80 & 8.46 & 8.68 & 8.79 \\
\hline$\sigma^{*}$ & 10.31 & 10.03 & 11.57 & 12.41 \\
\hline $\mathrm{C}-\mathrm{N}$ & & 11.74 & 14.08 & 18.08 \\
\hline \multicolumn{5}{|c|}{$\mathrm{XR}^{\prime}=\mathrm{NH}_{2} ; \mathrm{R}=\left(\mathrm{CH}_{3}\right)_{2}$} \\
\hline $\mathrm{Cr} 3 \mathrm{~d}_{y z}$ & 7.12 & 7.48 & 8.01 & 7.79 \\
\hline $\operatorname{Cr} 3 \mathrm{~d}_{x z}$ & 7.35 & 7.68 & 8.03 & 8.18 \\
\hline $\operatorname{Cr} 3 \mathrm{~d}_{x^{2}-y^{2}}$ & 7.61 & 7.93 & 8.54 & 8.60 \\
\hline$\sigma^{*}$ & 9.72 & 9.19 & 10.71 & 11.86 \\
\hline $\mathrm{C}-\mathrm{N}$ & 10.67 & 10.20 & 11.92 & 16.09 \\
\hline
\end{tabular}

TABLE 9: Bond Dissociation Energies (BDE, kcal/mol) of M- $\mathbf{C}_{\text {carbene }}$

\begin{tabular}{|c|c|c|c|}
\hline compound & $\mathrm{BDE}$ & type of calculation & ref \\
\hline \multirow[t]{5}{*}{$(\mathrm{CO})_{5} \mathrm{CrC}(\mathrm{OH})(\mathrm{C} \equiv \mathrm{CH})$} & 38.4 & $\mathrm{HFSCF}^{a}$ & this work \\
\hline & 76.2 & $\operatorname{CASSCF}(6,6)^{a}$ & this work \\
\hline & 76.8 & $\mathrm{DFT}(\mathrm{LDA})^{a}$ & this work \\
\hline & 54.9 & DFT(LDA/NL/BP) ${ }^{a}$ & this work \\
\hline & 48.5 & DFT(LDA/NL/BLYP $)^{a}$ & this work \\
\hline \multirow[t]{5}{*}{$(\mathrm{CO})_{5} \mathrm{CrC}\left(\mathrm{NH}_{2}\right) \mathrm{CH}_{3}$} & 40.5 & $\mathrm{HFSCF}^{a}$ & this work \\
\hline & 77.9 & $\operatorname{CASSCF}(6,6)^{a}$ & this work \\
\hline & 75.3 & $\operatorname{DFT}(\text { LDA })^{a}$ & this work \\
\hline & 54.0 & DFT(LDA/NL/BP) ${ }^{a}$ & this work \\
\hline & 47.3 & DFT(LDA/NL/BLYP) $)^{a}$ & this work \\
\hline \multirow[t]{2}{*}{$(\mathrm{CO})_{5} \mathrm{CrCH}_{2}$} & 66.4 & DFT(LDA/NL/BP) & $32 \mathrm{a}, \mathrm{c}$ \\
\hline & 66.9 & DFT(LDA/NL/BP) & $32 \mathrm{a}, \mathrm{c}$ \\
\hline$(\mathrm{CO})_{5} \mathrm{CrCH}(\mathrm{OH})$ & 44 & HFSCF & 7 \\
\hline$\left[(\mathrm{CO})_{5} \mathrm{MnCH}_{2}\right]^{+}$ & 75.9 & DFT(LDA/NL/BP) & $32 \mathrm{c}$ \\
\hline \multirow[t]{3}{*}{$(\mathrm{CO})_{5} \mathrm{MoCH}_{2}$} & 76.2 & $\operatorname{CASSCF}(8,8)$ & $32 \mathrm{c}, 21 \mathrm{a}$ \\
\hline & 55.7 & MCSCF(GMO-CI) & 19 \\
\hline & 60.5 & DFT(LDA/NL/BP) & $32(\mathrm{a}, \mathrm{c})$ \\
\hline \multirow[t]{5}{*}{$\mathrm{Cr}(\mathrm{CO})_{6}$} & 36.8 & experiment & 96 \\
\hline & 21.0 & $\mathrm{HF}$ & 97 \\
\hline & 62.1 & DFT(LDA) & 98 \\
\hline & 45.9 & DFT(LDA/NL/BP) & 99 \\
\hline & 36 & DFT(LDA/NL/BLYP) & 99 \\
\hline
\end{tabular}

${ }^{a}$ Refers to a dissociation into two singlet fragments being $6.0 \AA$ apart.
CASSCF result is not observed here, because the Fermi hole function is based on the HF calculation.

Ionization Potentials. Photoelectron spectroscopic data of nine pentacarbonylchromium-carbene complexes are available in the literature..$^{5}$ The corresponding molecular orbital (FenskeHall $)^{5}$ calculations are also available. The VIPs are calculated based on Koopmann's theory. ${ }^{60}$ We have calculated the ionization potentials of five carbene complexes using ab initio/ HF and DFT methods. The acquired values are listed in Table 8 in comparison with the measured ones. ${ }^{5}$ It is obvious that values obtained in this work are far closer to the experimental ones than those from earlier calculations, ${ }^{5}$ and values from DFT are better than those from HF. However it needs to be pointed out that the values from DFT are calculated on the basis of the transition state. ${ }^{61-63}$ If we plotted the calculated values with respect to the observed ones as a linear function, the slope in DFT values is often close to 1 , as found elsewhere. ${ }^{95}$ One example on the first compound $\left(\mathrm{XR}^{\prime}=\mathrm{NH}_{2}, \mathrm{R}=\mathrm{Ph}\right)$ is such that the slopes are 1.00, 1.57, and 2.92 and the intercepts are $0.37,-3.60$, and -13.50 respectively for DFT, ab initio/HF, and Fenske- Hall $^{5}$ calculations.

Bond Dissociation Energy. The BDEs of the metal carbene bond of Fischer-type carbenes have been investigated extensively. ${ }^{7,9,21,32}$ Relevant BDEs are given in Table 9. The earlier work based on HFSCF gave $44 \mathrm{kcal} / \mathrm{mol}$ for the $\mathrm{Cr}-$ $\mathrm{C}_{\text {carbene }}$ bond in $(\mathrm{CO})_{5} \mathrm{CrCH}(\mathrm{OH}) .{ }^{7}$ Calculations at the post $\mathrm{HF}$ level yielded 56 and $60 \mathrm{kcal} / \mathrm{mol}^{19}$ for the $\mathrm{Mo}-\mathrm{C}$ bond in $(\mathrm{CO})_{5^{-}}$ $\mathrm{MoCH}_{2}$ and $(\mathrm{CO})_{5} \mathrm{MoCH}(\mathrm{OH})$ respectively. The recent DFT calculation ${ }^{32}$ gives 67 and $76 \mathrm{kcal} / \mathrm{mole}$ for $(\mathrm{CO})_{5} \mathrm{CrCH}_{2}$ and $\left[(\mathrm{CO})_{5} \mathrm{MnCH}_{2}\right]^{+}$, respectively. Apparently, the effect on electron correlation and nonlocal correction on DFT is important in such BDEs. In this work, $\operatorname{BDEs}$ based on $\operatorname{CASSCF}(6,6)$ give 76 and $78 \mathrm{kcal} / \mathrm{mol}$ respectively for compounds $\mathbf{1}$ and $\mathbf{2}$. The ones based on DFT(LDA/NL/BP) give 55 and $54 \mathrm{kcal} / \mathrm{mol}$ correspondingly. The ones on DFT(LDA/NL/BLYP) give even lower energy of 48 and $47 \mathrm{kcal} / \mathrm{mol}$. The magnitude in energy difference of the BDE with and without nonlocal corrections (BP, BLYP) in these two compounds is similar to that of the $\mathrm{Cr}-\mathrm{C}$ bond in $\mathrm{Cr}(\mathrm{CO})_{6} \cdot{ }^{96-99}$ Unfortunately, no experimental value that we are aware of is available for the $\mathrm{Cr}-\mathrm{C}_{\text {carbene }}$ bond. However, on the basis of the $\mathrm{Cr}(\mathrm{CO})_{6}$ example (Table 9), the value from DFT with nonlocal correction BLYP gives the closest value to the experimental one. Both CASSCF and DFT/LDA results overestimate the energy, but the $\mathrm{HF}$ result underestimates the BDE.

\section{Conclusion}

This is a comparative study between experiment and theory that makes use of the energy, the electron density, and its topology. Experimental deformation density and topological analyses of compound $\mathbf{1}$ are in good agreement with those calculated from molecular orbital calculations. The asphericity in electron density around the $\mathrm{Cr}$ atom or the $\mathrm{d}$ orbital populations of $\mathrm{Cr}$ is in accord with the crystal field theory. Orbital energies calculated from DFT are close to the measured values from PES. The bonding characteristics of Fischer-type carbenes are as follows: the $\mathrm{Cr}-\mathrm{C}_{\text {carbene }} \sigma$ bond is formed by electron donating from the carbene carbon. The $\mathrm{Cr}-\mathrm{C}_{\text {carbene }} \pi$ bond is actually a $\mathrm{Cr}-\mathrm{C}-\mathrm{X}$ three-centered four-electron $\pi$ bond having the $\pi$ density largely located at both $\mathrm{Cr}$ and $\mathrm{X}$. The difference in bonding of carbenes between $\mathrm{X}=\mathrm{O}$ and $\mathrm{X}=\mathrm{N}$ 
(a)

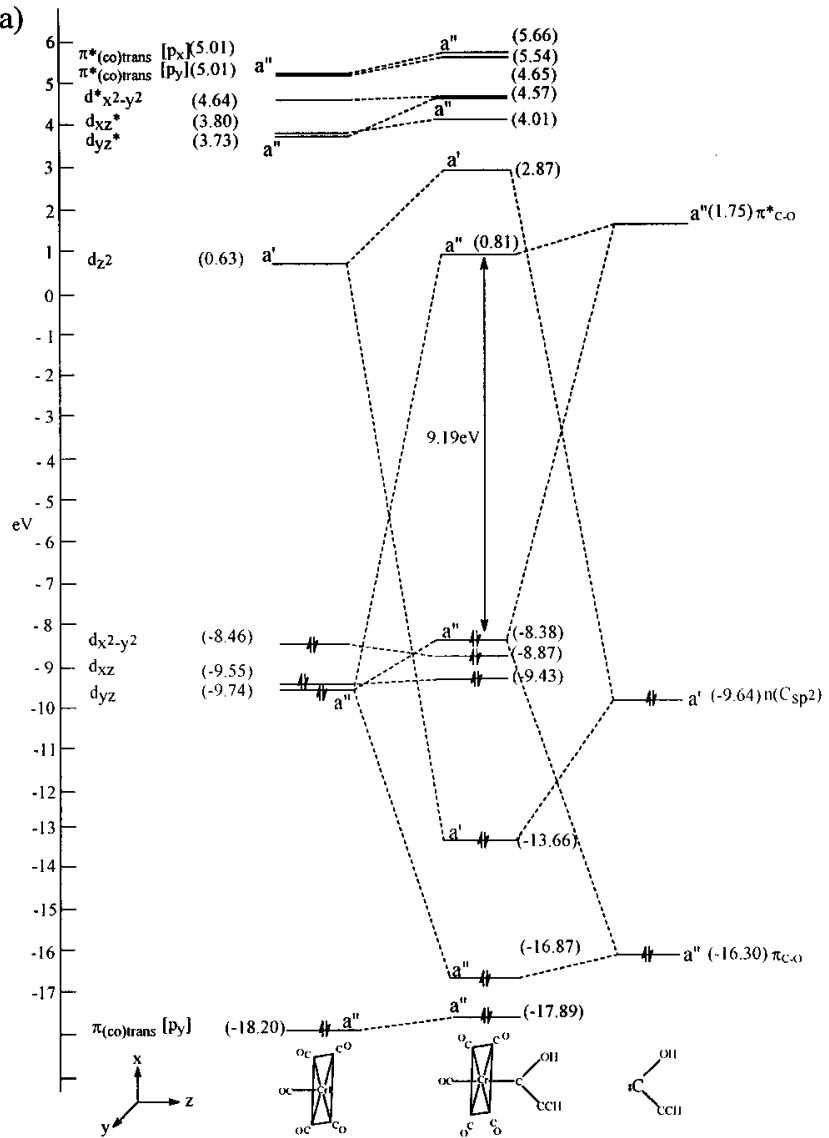

Figure 11. Orbital correlation diagram of (a) 1 and (b) 2 .

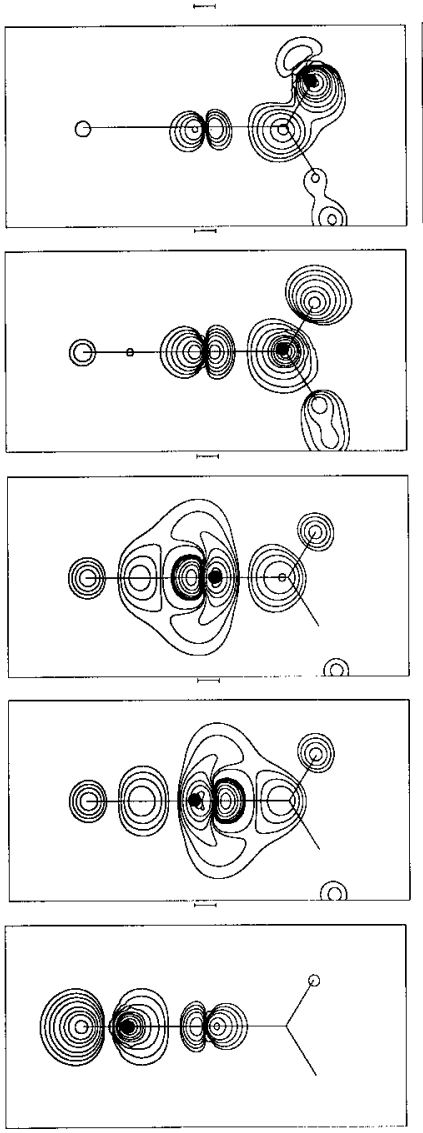

(I) $\mathrm{X}=\mathrm{O}$
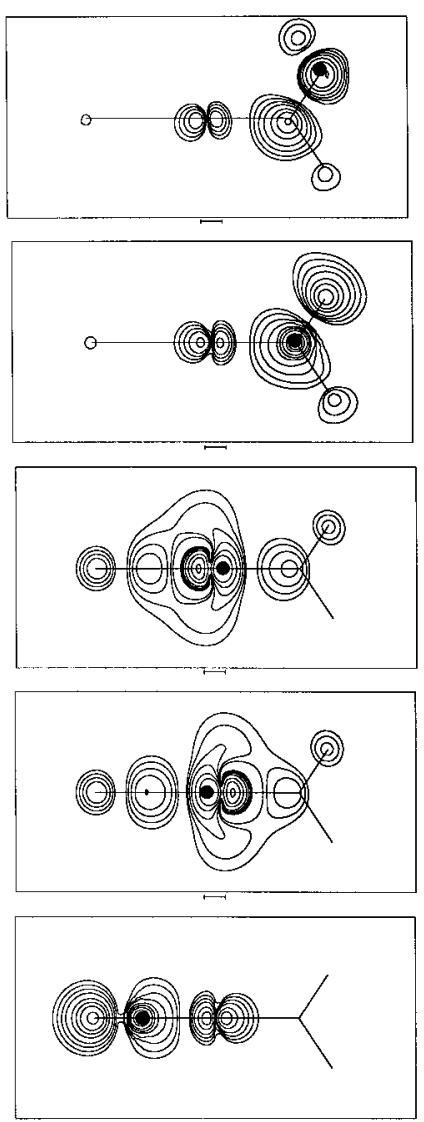

(2) $\mathrm{X}=\mathrm{N}$

Figure 12. Fermi hole density with the reference electron $(\bullet)$ placed at $0.5 \mathrm{au}$ above the plane. The right column is of $\mathbf{1}$ and the left column is of 2 . The contours are in atomic unit with $2^{i} \times 10^{j}(i=0,1,2,3$; $j=-3,-2,-1)$. (b)

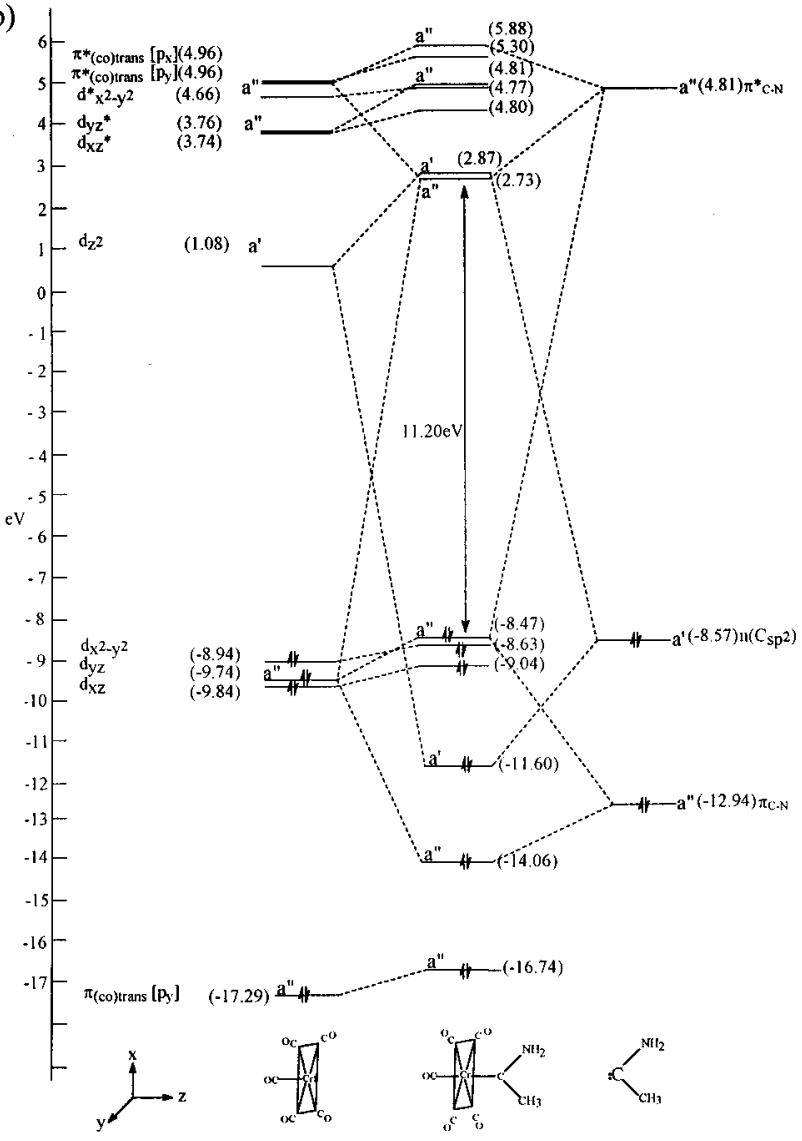

is in the $\mathrm{M}-\mathrm{CO}_{\text {trans }}$ bond. The summary of the bonding character is described in the following diagram.

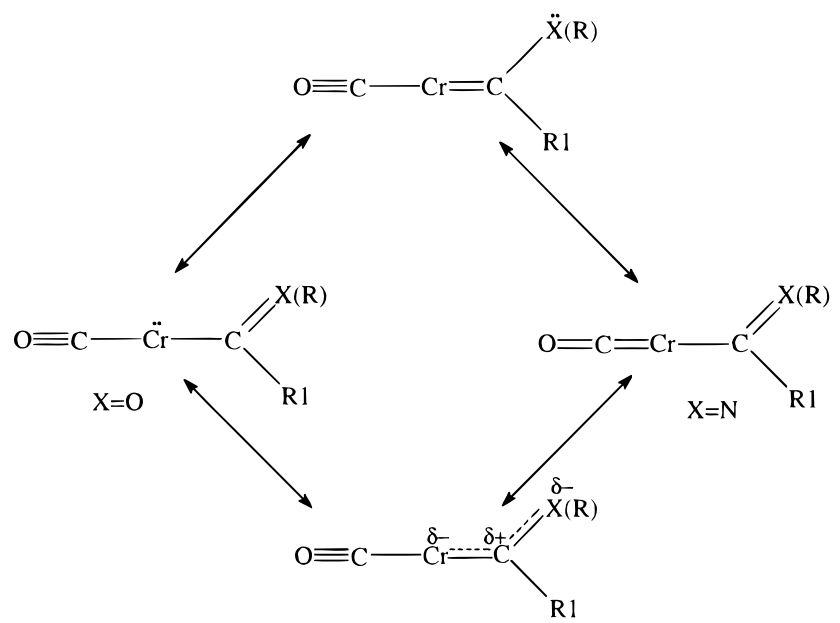

Acknowledgment. Financial support of this work from the National Science Council of ROC is appreciated. Thanks are due to the National Center for High Performance Computing for providing computing facilities and software packages. Special thanks go to Professor R. F. W. Bader, Professor N. Hansen, and Professor M. Souhassou for their kindly supplies of AIMPAC, SALLY, and PROP programs respectively.

Supporting Information Available: Tables of crystal data, atomic coordinates and thermal parameters, and bond distances and angles of compounds $\mathbf{1 - 4}$ and multipole coefficients of compound 1. Figures of negative Laplacian of electron density of 2, negative Laplacian around $\mathrm{Cr}$ of $\mathbf{2}$, gradient vector field of the electron density of $\mathbf{2}$, and total density, bond path, and 
atom domain of 2 (20 pages). Ordering information is given on any current masthead page.

\section{References and Notes}

(1) Collman, J. P.; Hegedus, L. S.; Norton, J. R.; Finke, P. G. Principles and Application of Organometallic Metal Chemistry; Mill Vally: CA, 1987.

(2) (a) Cardin, D. J.; Cetinkaga, B.; Lappert, M. F. Chem. Rev. (Washington, D.C.) 1972, 72, 545-574. (b) Adams, R. D. Chem. Rev. (Washington, D.C.) 1989, 89, 1703-1712.

(3) Fischer, E. O.; Maasböl, D. C. A. Angew. Chem., Int. Ed. Engl. 1964, 3, 580-581.

(4) (a) Schrock, R. R. J. Organomet. Chem. 1986, 300, 249-262. (b) Schrock, R. R. Acc. Chem. Res. 1979, 12, 98-104. (c) Schrock, R. R. Acc. Chem. Res. 1990, 23, 158-165. 4330 .

(5) Block, T. F.; Fenske, R. F. J. Am. Chem. Soc. 1977, 99, 4321-

(6) Spangler, D.; Wendoloski, J. J.; Dupuis, M.; Chen, M. M. L.; Schaefer, H. F., III. J. Am. Chem. Soc. 1981, 103, 3985-3990.

(7) Nakatsuji, H.; Ushio, J.; Han, S.; Yonezawa, T. J. Am. Chem. Soc. 1983, 105, 426-434.

(8) Goddard, R. J.; Hoffmann, R.; Jemmis, E. D. J. Am. Chem. Soc. 1980, 102, 7667-7676.

(9) Volatron, F.; Eisenstein, O. J. Am. Chem. Soc. 1986, 108, 21732179.

(10) Block, T. F.; Fenske, R. F.; Casey, C. P. J. Am. Chem. Soc. 1976, 98, 441-443. 4685 .

(11) Kostic, N. M.; Fenske, R. F. J. Am. Chem. Soc. 1981, 103, 4677-

(12) Hall, M. B.; Fenske, R. F. Inorg. Chem. 1972, 11, 768-775.

(13) Kostic, N. M.; Fenske, R. F. Organometallics 1982, 1, 489-496.

(14) Francl, M. M.; Pietro, W. J.; Hout, R. F.; Hehre, W. J. Organometallics 1983, 2, 281-286.

(15) Rappé, A. K.; Goddard, W. A., III. J. Am. Chem. Soc. 1977, 99, 3966-3968

(16) Rappé, A. K.; Goddard, W. A., III. J. Am. Chem. Soc. 1982, 104, $448-456$.

(17) Carter, E. A.; Goddard, W. A., III. J. Am. Chem. Soc. 1986, 108, 4746-4754.

(18) Marynick, D. S.; Kirkpatrick, C. M. J. Am. Chem. Soc. 1985, 107, 1993-1994.

(19) Taylor, T. E.; Hall, M. B. J. Am. Chem. Soc. 1984, 106, 15761584.

(20) Biré, A. S.; Dao, N. Q.; Strich, A.; Thieffry, C.; Bénard, M. Inorg. Chem. 1990, 29, 4908-4915.

(21) (a) Márquez, A.; Sanz, J. F. J. Am. Chem. Soc. 1992, 114, 29032909. (b) Márquez, A.; Sanz, J. F. J. Am. Chem. Soc. 1992, 114, 1001910024. (c) Selmani, A.; Salahub, D. R. J. Chem. Phys. 1988, 89, 15291532.

(22) Cundari, T. R.; Gordon, M. S. J. Am. Chem. Soc. 1991, 113, 52315243.

(23) Cundari, T. R.; Gordon, M. S. J. Am. Chem. Soc. 1992, 114, 539548.

(24) Roos, B. O.; Taylor, P. R.; Siegbahn, P. E. M. Chem. Phys. 1980, 48, 157-173.

(25) Siegbahn, P. E. M.; Almlöf, J.; Heiberg, A.; Roos, B. O. J. Chem. Phys. 1981, 74, 2384-2396. 324.

(26) Mcdouall, J. J. W.; Robb, M. A. Chem. Phys. Lett. 1986, 132, 319-

(27) Ruedenberg, K.; Schmidt, M. W.; Gilbert, M. M.; Elbert, S. T. Chem. Phys. 1982, 71, 41-49.

(28) Ruedenberg, K.; Schmidt, M. W.; Gilbert, M. M. Chem. Phys. 1982, $71,51-64$.

(29) Poblet, J. M.; Strich, A.; Wiest, R.; Bénard, M. Chem. Phys. Lett. 1986, 126, 169-175.

(30) Ziegler, T. Pure Appl. Chem. 1991, 28, 1271.

(31) Ziegler, T. Chem. Rev. (Washington, D.C.) 1991, 91, 651-667.

(32) (a) Jacobsen, H.; Schreckenbach, G.; Ziegler, T. J. Phys. Chem. 1994, 98, 11406-11410. (b) Jacobsen, H.; Ziegler, T. Organometallics 1995, 14, 224-230. (c) Jacobsen, H.; Ziegler, T. Inorg. Chem. 1996, 35, 775783.

(33) Bader, R. F. W. Atoms in Molecules, A Quantum Theory; Calendron Press: Oxford, 1990.

(34) Bader, R. F. W.; Essén, H. J. Chem. Phys. 1984, 80, 1943-1960.

(35) Carroll, M. T.; Cheeseman, J. R.; Osman, R.; Weinstein, H. J. Phys. Chem. 1989, 93, 5120-5123.

(36) Bader, R. F. W.; Nguyen-Dang, T. T.; Tal, Y. J. Chem. Phys. 1979, 70, 4316-4329.

(37) Zou, P. F.; Bader, R. F. W. Acta. Crystallogr. 1994, A50, 714725 .

(38) Chan, K. S.; Wulff, W. D. J. Am. Chem. Soc. 1986, 108, 52295236.

(39) International Tables for X-ray Crystallography; Kynoch Press: Birmingham, U.K., 1974; Vol. IV.
(40) (a) Coppens, P.; Hall, M. B. Electron Distribution and the Chemical Bond; Plenum Press, New York, 1982. (b) Hansen, N. K.; Coppens, P. Acta. Crystallogr. 1978, A34, 909-921. (c) Program producing static deformation density by Dr. N. K. Hansen, at the University of Nancy, France.

(41) Gabe, E. J.; Le Page, Y.; Charland, J.-P.; Lee, F. L.; White, P. S. J. Appl. Crystallogr. 1989, 22, 384-385.

(42) PROP program: A program developed by Sauhassou, M.; Hansen, N. K.; Stevens, E.; Craven, B.; Bouhmeida, N.; Ghermani, N.; Lecomte, C. 1982.

(44) Rappe, A. K.; Smedley, T. A.; Goddard, W. A., III. J. Phys. Chem. 1981, 85, 2607-2611.

(45) Wachters, A. J. H. J. Chem. Phys. 1970, 52, 1033-1036.

(46) (a) von Barth, U.; Hedin, L. J. Phys. C 1972, 5, 1629-1642. (b) Versluis, L.; Ziegler, T. J. Chem. Phys. 1988, 88, 3322-3330. (c) Hirshfeld, F. L. Theor. Chim. Acta. 1977, B44, 129.

(47) Vosko, S. J.; Wilk, L.; Nusair, M. Can. J. Phys. 1980, 58, 12001211.

(48) Becke, A. D. J. Chem. Phys. 1986, 84, 4524-4529. (b) Becke, A. D. J. Chem. Phys. 1988, 88, 1053-1062.

(49) Perdew, J. P. Phys. Rev. 1986, B33, 8822

(50) Reed, A. E.; Weinhold, F. J. Chem. Phys. 1985, 83, 1736-1740.

(51) Foster, J. P.; Weinhold, F. J. Am. Chem. Soc. 1980, 102, 72117218.

(52) Reed, A. E.; Curtiss, L. A.; Weinhold, F. Chem. Rev. (Washington, D.C.) 1988, 88, 899-926.

(53) Reed, A. E.; Weistock, R. B.; Weinhold, F. J. Chem. Phys. 1985, $83,735-746$.

(54) Löwdin, P. O. Phys. Rev. 1955, 97, 1474-1489.

(55) (a) Pauling, L. J. Am. Chem. Soc. 1931, 53, 1367-1400. (b)

Coulson, C. A. Valence, 2nd ed.; Oxford University Press: London, 1952.

(56) McWeeny, R.; Diercksen, G. J. Chem. Phys. 1968, 49, 4852-4856.

(57) McWeeny, R. Rev. Mod. Phys. 1960, 32, 335.

(58) Bader, R. F. W.; Stephens, M. E. Chem. Phys. Lett. 1974, 26, 445.

(59) Bader, R. F. W.; Stephens, M. E. J. Am. Chem. Soc. 1975, 97, $7391-7399$

(60) Koopmans, T. Physica (Utrecht) 1933, 1, 104.

(61) Slater, J. C. Adv. Quantum Chem. 1972, 6, 1.

(62) Asbrink, L.; Fridh, C.; Lindholm, E. Chem. Phys. Lett. 1977, 52, $69-71$.

(63) Chong, D. P. J. Chin. Chem. Soc. 1992, 6, 20.

(64) Frisch, M. J.; Trucks, G. W.; Schlegel, H. B.; Gill, P. M. W.; Johnson, B. G.; Robb, M. A.; Cheeseman, J. R.; Keith, T. A.; Petersson, G. A.; Montgomery, J. A.; Raghavachari, K.; Al-Laham, M. A.; Zakrzewski, V. G.; Martin, R. L.; Ortiz, J. V.; Foresman, J. B.; Cioslowski, J.; Stefanov, B. B.; Nanayakkara, A.; Challacombe, M.; Peng, C. Y.; Ayala, P. Y.; Chen, W.; Wong, M. W.; Andres, J. L.; Replogle, E. S.; Gomperts, R.; Martin, R. L.; Fox, D. J.; Binkley, J. S.; Defrees, D. J.; Baker, J.; Stewart, J. P.; Head-Gordon, M.; Gonzalez, C.; Pople, J. A. Gaussian 94 (Revision A.1); Gaussian Inc.: Pittsburg, PA, 1995.

(65) Delley, B. J. Chem. Phys. 1990, 92, 508-517.

(66) Lichtenberger, D. L.; Fenske, R. F. MOPLOT. QCPE 1975.

(67) AIMPAC: a set of programs for the Theory of Atoms in Molecules: Bader, R. F. W., co-workers, Eds.; McMaster University, Hamilton, Ontario, Canada.

(68) Mills, O. S.; Redhouse, A. D. J. Chem. Soc. A 1968, 642-647.

(69) Huttner, G.; Lorenz, H. Chem. Ber. 1975, 108, 1864-1870.

(70) (a) Perry, W. B.; Schaaf, T. F.; Jolly, W. L. Inorg. Chem. 1974, 13, 2038-2329. (b) Kruger, C.; Goddard, R.; Claus, K. H. Z. Naturforsch. 1983, B38, 1431 .

(71) Dotz, K. H.; Kuhn, W.; Ackermann, K. Z. Naturforsch. 1983, B38, 1351.

(72) Dotz, K. H.; Kuhn, W.; Thewalt, U. Chem. Ber. 1985, 118, 1126. (73) Klingler, R. J.; Huffman, J. C.; Kochi, J. K. Inorg. Chem. 1981, 20, 34-40.

(74) Aumann, R.; Hinterding, P.; Kruger, C.; Betz, P. Chem. Ber. 1990, 123,1847

(75) Sabat, M.; Gross, M. F.; Finn, M. G. Organometallics 1992, 11, $745-751$.

(76) Baikie, P. E.; Fischer, E. O.; Mills, O. S. Chem. Comm. 1967, 1199. (77) Connor, J. A.; Mills, O. S. J. Chem. Soc. A 1969, 334-341.

(78) Rudler, H.; Parlier, A.; Yefsah, R.; Denise, B.; Daran, J. C.; Vaissermann, J.; Knobler, C. J. Organomet. Chem. 1988, 358, 245-272. (79) Alvarez, C.; Parlier, A.; Rudler, H.; Yefsah, R.; Daran, J. C.; Knobler, C. Organometallics 1989, 8, 2253-2259.

(80) Denise, B.; Goumont, R.; Parlier, A.; Rudler, H.; Daran, J. C.; Vaissermann, J. J. Organomet. Chem. 1989, 377, 89-104.

(81) Barluenga, J.; Aznar, F.; Martín, A.; García-Granda, S.; PérezCarreño, E. J. Am. Chem. Soc. 1994, 116, 11191-11192.

(82) Yang, D. C.; Dragisich, V.; Wulff, W. D.; Huffman, J. C. J. Am. Chem. Soc. 1988, 110, 307-309.

(83) Huttner, G.; Lange, S. Chem. Ber. 1970, 103, 3149. 
(84) Cotton, F. A.; Richardson, D. C. Inorg. Chem. 1966, 5, 18511854.

(85) Gleichmann, M. M.; Dötz, K. H.; Hess, B. A. J. Am. Chem. Soc. 1996, 118, 10551-10560.

(86) Fabius, B.; Cohen-Addad, C.; Larsen, F. K.; Lehmann, M. S.; Becker, P. J. Am. Chem. Soc. 1989, 111, 5728-5732.

(87) Schwarz, W. H. E.; Ruedenberg, K.; Mensching, L. J. Am. Chem. Soc. 1989, 111, 6926-6933.

(88) Kunze, K. L.; Hall, M. B. J. Am. Chem. Soc. 1987, 109, 76177623.

(89) Dunitz, J. D.; Seiler, P. J. Am. Chem. Soc. 1983, 105, 7056.

(90) (a) Cioslowski, J.; Hay, P. J.; Ritchie, J. P. J. Phys. Chem. 1990 94, 148-151. (b) Wang, C. C.; Wang, Y.; Chou, L. K.; Che, C. M. J. Phys. Chem. 1995, 99, 13899-13008. (c) Lee, C. S.; Hwang, T. S.; Wang. Y.; Peng, S. M.; Hwang, C. S. J. Phys. Chem. 1996, 100, 2934-2941.

(91) (a) Wulff, W. D.; Bauta, W. E.; Kaesler, R. W.; Lankford, P. J.; Miller, R. A.; Murray, C. K.; Yang, D. C. J. Am. Chem. Soc. 1990, 112, 3642-3659. (b) Wulff, W. D.; Yang, D. C. J. Am. Chem. Soc. 1984, 106, $7565-7567$.
(92) Sustmann, R.; Trill, H. Angew. Chem., Int. Ed. Engl. 1972, 11, 838-839.

(93) Bader, R. F. W.; Streitwieser, A.; Neuhaus, A.; Laidig, K. E.; Speers, P. J. Am. Chem. Soc. 1996, 118, 4959-4965.

(94) Bader, R. F. W.; Johnson, S.; Tang, T.-H.; Popelier, P. L. A. J. Phys. Chem. 1996, 100, 15398-15415.

(95) Hwang, T. S.; Chong, D. P.; Wang, Y. J. Chin. Chem. Soc. 1994, $41,673-677$.

(96) Lewis, K. E.; Golden, D. M.; Smith, G. P. J. Am. Chem. Soc. 1984, 106, 3905-3912.

(97) Ehlers, A. W.; Frenking, G. J. Am. Chem. Soc. 1994, 116, 15141520.

(98) (a) Li, J.; Schreckenbach, G.; Ziegler, T. J. Am. Chem. Soc. 1995, 117, 486-494. (b) Li, J.; Schreckenbach, G.; Ziegler, T. J. Phys. Chem. 1994, 98, 4838-4841.

(99) Jonas, V.; Thiel, W. J. Chem. Phys. 1995, 102, 8474-8484. 